\title{
Durable-goods oligopoly with secondary markets: the case of automobiles
}

\author{
Susanna Esteban *
}

Matthew Shum **

We study the effects of durability and secondary markets on equilibrium firm behavior in the car market. We construct a dynamic oligopoly model of a differentiated product market to incorporate the equilibrium production dynamics which arise from the durability of the goods and their active trade in secondary markets. We derive an econometric model and estimate its parameters using data from the automobile industry over a twenty-year period. Our estimates are used to provide a measure of the competitive importance of the secondary market.

*: Department of Economics, Universidad Carlos III de Madrid; sesteban@eco. uc3m. es

**: Department of Economics, Johns Hopkins University; ms hume jhu . edu

We thank the Editor and two anonymous referees for detailed comments. We thank Steve Berry, Eric Bond, Jean-Pierre Dubé, Alessandro Gavazza, Joe Harrington, Hugo Hopenhayn, Ozgur Kibris, Alessandro Lizzeri, Sumon Majumdar, Ariel Pakes, Mark Roberts, Marc Rysman, Shannon Seitz, Nadia Soboleva, Jim Tybout, and participants at many universities and conferences. We thank Jian Hong, Sunghwan Kim, Andy Kotikula, and Yi Lee for remarkable research assistance. 


\section{Introduction}

In many durable goods industries, used products are traded in decentralized secondary markets which are not directly controlled by the producers of new goods: the automobile industry is perhaps the most prominent example. In this paper we seek to understand the effects of durability and secondary markets on equilibrium production behavior in this industry. In the context of a dynamic equilibrium model, we model explicitly how product durability and trade in secondary markets affects equilibrium producer behavior in the automobile market.

The durability of cars and the existence of a secondary market have important competitive implications for new car producers. The secondary market introduces, in the form of used cars, a large number of (imperfect) substitutes to the new cars produced each period, which limits the market power of each producer. In turn, rational firms recognize that their current production will reach the secondary market in the future and, by lowering prices in those markets, will erode future profits. A monopolist fully internalizes this effect by curtailing current production. In an oligopoly, however, each producer internalizes only the effect this has on its own future profits, but not the detrimental effect it has on its rivals' future profits. ${ }^{1}$ Indeed, each oligopolistic producer derives an indirect benefit from increases in current production if this causes its rivals to lower their future production levels; in equilibrium, therefore, a firm may choose to overproduce today if these indirect benefits outweigh the costs of more vigorous competition tomorrow.

Moreover, the presence of a secondary market also introduces an additional component — the resale value - to consumers' valuations of new cars. This dependence of new car valuations on expected future prices introduces an intertemporal linkage between a firm's current profits and its own future behavior, as well as the future behavior of its competitors. Given these linkages, the firm wishes to commit to low levels of production in the future to increase the expected resale value. Such behavior, however, would not be time consistent, because once the future arrives, the firm no longer cares about its past profits, and is tempted to increase its production. Rational consumers will anticipate the firm's future actions and expect low resale prices, thus curbing current demand.

The intertemporal linkages between each firm's current profits and its own current, past and future production, as well as the current, past and future production of its rivals, makes for a rich dynamic game. In this paper, we examine the equilibrium dynamics of this game within the context of the automobile industry. First, we construct a dynamic oligopoly model of a differentiated product market which incorporates durability of the goods and their active trade in secondary markets. Second, we use data from the automobile market to estimate a tractable linear-quadratic version of the model.

\footnotetext{
${ }^{1}$ This dynamic effect was also identified in (Carlton and Gertner, 1989).
} 
While the empirical model is quite stylized, and incorporates restrictive assumptions, it represents (as far as we are aware) a first attempt at structural estimation of a dynamic durable goods model for this industry.

\section{Background and existing literature}

As the discussion above emphasized, durability and secondary markets introduces dynamics into both producers' output decisions and consumers' purchase decisions in the automobile market, which creates challenges for both theoretical and empirical work. In this paper, we overcome these challenges by constructing a dynamic equilibrium model of the car market in which tractability is provided by its linear-quadratic structure. ${ }^{2}$ Our model captures four key characteristics of the car industry: ( $i$ ) oligopolistic time-consistent multi-product automobile producers; (ii) an active, decentralized secondary market; (iii) differentiated products; and (iv) depreciation schedules which differ across the competing car models.

However, we make some restrictive assumptions in deriving the linear-quadratic model: (a) consumers face no transactions costs in buying or selling cars, which makes the secondary market active by increasing the substitutability between new and used cars; $(b)$ the automobile market is vertically differentiated, which places strong restrictions on the substitutability between cars in consumers' choice sets; and $(c)$ there is perfect information, so we abstract away from adverse selection issues. ${ }^{3}$ While the resulting model is quite stylized, our empirical results demonstrate the feasibility of estimating a dynamic durable goods model for this industry and, we hope, encourage future progress.

Since the seminal work of (Coase, 1972), a large theoretical literature has analyzed how durability erodes market power for a monopoly producer. ${ }^{4}$ Coase conjectured that a monopolist producing an infinitely-durable good may lose all of its market power due to its inability to commit to high prices (or low production) in the future. (Stokey, 1981; Gul, Sonnenschein, and Wilson, 1986; Ausubel and Deneckere, 1989) showed how Coase's conjecture can arise as an equilibrium limiting result in models where the time lag between the monopolist's price offers shrinks to zero. ${ }^{5}$ In

\footnotetext{
${ }^{2}$ See (Kydland, 1975) for a description of discrete-time linear-quadratic dynamic games, and (Judd, 1996) for an application to dynamic oligopoly models where firms set both prices and quantities. Also in a linear-quadratic setting, (Kahn, 1986) analyzes the effects of increasing costs in an infinitely-durable goods monopoly.

${ }^{3}$ Adverse selection has been a concern in the literature on secondary markets since (Akerlof, 1970). See (Hendel and Lizzeri, 1999) and (House and Leahy, 2000) for recent contributions to this literature, and (Bond, 1982) for related empirical work.

${ }^{4}$ See (Waldman, 2003) for a recent survey.

${ }^{5}$ See also (Bulow, 1982) for a treatment of the durable-goods monopolist problem within a two-period model.
} 
the presence of Coasian commitment problems, (Liang, 1999) shows that a secondary market can reduce the monopolist's temptation to increase future output, because it reduces competition with the secondary market by selling more slowly to consumers, thus nearing the commitment solution.

The implications of durability and secondary markets on the dynamics of car demand have not been ignored in the literature. (Berkovec, 1985; Rust, 1985a; Stolyarov, 2002) focus on dynamic consumer demand in a durable goods market with primary, secondary and scrappage market segments. (Adda and Cooper, 2000) employ the optimal decision rules from a dynamic discrete-choice model to explore the effects of scrappage subsidies on car demand, where cars are held until scrapped and, hence, are not actively traded in the secondary market. Finally, (Eberly, 1994; Attanasio, 2000) consider $(s, S)$ models of automobile demand in which idiosyncratic shocks lead consumers to change their stock of cars. In all these papers, the focus is on the timing of consumer purchases, so that automobile prices are assumed to evolve exogenously, and firms' automobile production decisions are not explicitly modeled. In our paper, we model firms' equilibrium production decisions in a dynamic oligopoly model, but abstract away from consumer transactions costs in order to ensure the tractability of the model.

Our emphasis on the equilibrium dynamics due to durability and secondary markets also distinguishes our work from existing market-level empirical studies of demand and supply in the automobile market. (Bresnahan, 1981; Berry, Levinsohn, and Pakes, 1995; Goldberg, 1995; Petrin, 2002) have employed static models to quantify the degree of market power and the welfare effects of new product introductions in the car industry. These papers have focused on accommodating multiple dimensions of consumer heterogeneity in modeling the demand for automobiles. While some of these authors have allowed consumers to substitute between new and used cars in their models, they have not accommodated the intertemporal link between primary and secondary markets (i.e., that new cars today become used cars in the future), which is a crucial feature of our model. However, in order to maintain tractability in the dynamic oligopoly model, we restrict ourselves to a single-dimensional model of consumer heterogeneity.

Several papers have considered the empirical implications of durability and monopoly power. (Suslow, 1986) estimated a structural model of Alcoa's aluminum monopoly, taking into account the competition from the recycled aluminium sector. (Iizuka, 2007; Chevalier and Goolsbee, 2005) studied producer and consumer behavior in the academic textbook market. For the automobile industry, (Ramey, 1989) estimated a durable goods monopoly model to explain aggregate trends in car prices, and (Porter and Sattler, 1999) tested empirical predictions on the volume of trade in secondary car markets using a durable-goods monopoly model with transactions costs. There have been fewer papers on durable goods oligopoly. (Carlton and Gertner, 1989) analyzed the effects of merg- 
ers among oligopolistic durable goods producers, and (Esteban, 2002) characterizes the equilibrium production dynamics in a durable-goods oligopoly with homogeneous products.

The paper proceeds as follows. In Section 2 we introduce the model and derive the Markov perfect equilibrium of the dynamic game. Subsequently, we derive a linear-quadratic specification of this model which is convenient for the empirical illustration. In Section 3 we describe the data and discuss the empirical implementation of the model. In Section 4 we describe our estimation results and conduct some counterfactual experiments. We conclude in Section 5.

\section{A model of a durable goods oligopoly with secondary markets}

We consider a dynamic quantity-setting game among oligopolistic producers of differentiated durable goods (which, for convenience, we call "cars"). On the demand side, we assume that consumers are forward looking, so that durability and secondary markets introduce investment considerations into their car consumption decisions. On the supply side, we assume that new car producers are quantity-setting oligopolists which recognize both the intertemporal effect of current production on future profits due to the secondary market as well as the dependence of current profits on past, present, and expected future production. Several institutional features support a quantity-setting assumption. First, an implicit assumption of the Bertrand price-setting model is flexible capacity, and capacity does not appear easily adjustable in car production (cf. (Bresnahan and Ramey, 1994)). Second, in the car market prices seem to adjust to clear the market at given quantity levels, as in the quantity-setting case. For example, rebates are a common way of adjusting new car prices to clear the inventories at the end of the model year. Finally, dealer behavior limits the manufacturers' ability to control prices.

Since the model we derive in this paper is linear-quadratic, we focus on a deterministic version of the model, because the certainty equivalence property of linear-quadratic models ensures that the same equilibrium decision rules would obtain in its stochastic counterpart. For simplicity and tractability, we assume a stationary market environment, and do not consider the entry and exit of car models from the market.

Following (Esteban, 1999), we assume that the available cars are vertically differentiated. We refer to cars in their first period of life as new cars and, thereafter, as used cars. Throughout, we assume that used cars are transacted in competitive and decentralized secondary markets, so that new car producers can manipulate market outcomes in the secondary market only indirectly, through their production of new cars. 
Each period, $N$ firms produce new cars. We let $\mathcal{N}$ denote the set of firms, where $N \equiv|\mathcal{N}|$. Each firm $j \in \mathcal{N}$ produces $L_{j}$ distinct models, where $L_{j} \equiv\left|\mathcal{L}_{j}\right|$ and $\mathcal{L}_{j}$ is the set of all models produced by firm $j$. Then, $\mathcal{L} \equiv \cup_{j} \mathcal{L}_{j}$ is the set of all models produced by all firms and $L \equiv|\mathcal{L}|$ is their total number. We index models by $i=1, \ldots, L$.

New cars differ in quality and durability. For each model $i \in \mathcal{L}$, we let $q_{i, h}$ denote its quality at age $h$, where $h=1, \ldots, T_{i}$ indexes its age and $T_{i}<\infty$ denotes the number of periods it lasts. Then, each car (new or used) is completely described by the pair $(i, h)$, and the set of all distinct cars transacted is given by $\mathcal{K} \equiv\left\{(i, h) \mid i \in \mathcal{L}, h=1, \ldots, T_{i}\right\}$ and $K \equiv|\mathcal{K}|$ is their total number. Consumers have the opportunity to choose not only which model $i \in \mathcal{L}$ they drive, but also the vintage $h \in\left\{1, \ldots, T_{i}\right\}$. In the rest of this paper, we use the term "model-year" to denote the elements of $\mathcal{K}$, which are the set of choices available to consumers each period. As we remarked before, we assume that the market is stationary, in the sense that the set of available models $\mathcal{L}$ and model-years $\mathcal{K}$ do not change over time.

Next, we define a mapping $\omega: \mathcal{K} \mapsto\{1, \ldots, K\}$ which ranks cars from highest to lowest quality as follows

$$
\forall(i, h) \in \mathcal{K}, q_{i, h}>q_{i^{\prime}, h^{\prime}} \Rightarrow \omega(i, h)<\omega\left(i^{\prime}, h^{\prime}\right)
$$

Hence, a ranking of 1 denotes the highest-quality car, and a ranking of $K$ the lowest quality. Given this ranking, we define a quality ladder as follows.

Definition: A vector $\boldsymbol{\alpha}=\left[\alpha_{1}, \alpha_{2}, \ldots, \alpha_{K}, 0\right]^{\prime}$ is a quality ladder representing the quality structure of this problem if $\alpha_{k} \equiv\left\{q_{i, h} \mid k=\omega(i, h)\right\}$.

To facilitate the subsequent exposition, it is convenient to define a depreciation schedule for each car model as follows. Given a quality ladder $\boldsymbol{\alpha}$, we define a second mapping $v:\{1, \ldots, K\} \mapsto$ $\{1, \ldots, K\}$ which tracks the position that a car currently in position $k$ in the ladder occupies after one period of depreciation. Then, $v(\omega(i, 1))=\omega(i, 2)$ and, more generally,

$$
v^{h-1}(\omega(i, 1)) \equiv \underbrace{v(v(\ldots v}_{h-1 \text { times }}(\omega(i, 1))))=\omega(i, h), \quad \text { for } h=2, \ldots, T_{i}-1 .
$$

Cars which die (i.e., all cars $(i, h)$ where $h>T_{i}$ ) are given a ranking of $K+1$ (since $\alpha_{K+1}=0$ ), so that $v^{T_{i}}(\omega(i, 1))=K+1$, for all $i \in \mathcal{L}$, and $v(K+1)=K+1$. The mapping $v(\cdot)$ depends only on a model-year's rank, and only indirectly on the model $i$ or vintage $h$.

Finally, we let $\eta(i) \equiv \omega(i, 1)$, for all $i \in \mathcal{L}$, denote the position that a model $i$ car takes in the quality 
ladder when new. Then, we represent the depreciation schedule of a model $i$ car by the sequence

$$
\eta(i), v(\eta(i)), v^{2}(\eta(i)), \ldots v^{T_{i}}(\eta(i)),
$$

which indicates the positions in the ladder that a model $i$ car occupies as it ages. We now turn to the demand side of our model.

\section{Demand in a vertically differentiated market}

Our consumer population is a continuum of infinitely-lived agents in which heterogeneity in consumers' taste for quality generates demand for each type of car. In each period $t$, each consumer determines her optimal consumption choice among the $K$ available cars and the option of not consuming a car at all (which we index $K+1$ ), to maximize her discounted utility function.

We assume that consumers face no transactions costs in any primary or secondary market, which is a key assumption to obtain the linear-quadratic structure of the model. ${ }^{6}$ Without transaction costs the secondary market is very active, which may overstate the substitutability between new and used automobiles for consumers. In deriving consumers' optimal car choice rules, we assume that consumers have rational expectations about future production decisions for all firms in all car markets.

Heterogeneity among consumers is parameterized by a scalar type $\theta \in[0, \bar{\theta}]$ (where $\bar{\theta}<\infty$ ), and is distributed in the population according to the cumulative distribution $F(\cdot)$. To obtain the tractable linear-quadratic specification that we take to the data, we assume that $\theta$ is uniformly distributed along its support, so that $F(\theta)=\frac{\theta}{\theta}$, for $\theta \in[0, \bar{\theta}]$.

The population has size $M$. A consumer of type $\theta$ chooses a sequence of car choices to maximize her discounted lifetime utility

$$
U^{\theta} \equiv \sum_{t=1}^{\infty} \delta^{t-1} U_{t}^{\theta} .
$$

Her period $t$ utility flow is assumed to be quasilinear in income and given by

$$
U_{t}^{\theta} \equiv \alpha_{k} \theta+m_{t}^{\theta}-p_{t}^{k}
$$

where $\delta$ denotes the discount factor common across all consumers and firms, $\theta$ measures this consumer's willingness-to-pay for quality, and $m_{t}^{\theta}$ denotes consumer $\theta$ 's income at the beginning of

\footnotetext{
${ }^{6}$ Without this assumption, the individual-level dynamic demand functions would be involved as the decision for each consumer would depend on her past and future purchases; see, for instance, (Eberly, 1994). See also footnote 8.
} 
period $t$, which can include the resale price for a used car if the consumer is endowed with one in $t^{7}$

As is well known (eg., (Berkovec, 1985; Rust, 1985a)), the assumptions of quasilinearity and no transaction costs imply that a consumer's optimal consumption decision in any period does not depend on her past and future choices, because her decisions are independent of income. ${ }^{8}$ Then, it is easy to verify that consumer $\theta$ 's optimal car choice in period $t$ is determined by simply comparing the utility gains

$$
U G_{t}^{k}(\theta) \equiv \alpha_{k} \theta-p_{t}^{k}+\delta p_{t+1}^{v(k)}
$$

across all choices $k=1, \ldots, K+1$. Each utility gain is just the difference of $\alpha_{k} \theta$, the flow of services consumer $\theta$ obtains from car $k$ in period $t$, and $\rho_{t}^{k} \equiv\left(p_{t}^{k}-\delta p_{t+1}^{v(k)}\right)$, the implicit rental price paid for those services, where $\delta p_{t+1}^{v(k)}$ is the discounted resale price in tomorrow's secondary market. In every period, therefore, the optimal decision rule dictates that consumer $\theta$ chooses the car $k=1, \ldots, K+1$ which maximizes the utility gain given in Eq. (3).

\section{Deriving the demand functions}

The consumers' preferences specified above imply that competing cars are vertically differentiated, in the sense that if all cars were priced identically, all consumers would choose the highest quality car. Following the literature on oligopoly models of vertically-differentiated product markets (eg. (Prescott and Visscher, 1977; Bresnahan, 1981; Berry, 1994)), we derive the period $t$ demand functions as follows. ${ }^{9}$

Given prices $p_{t}^{k}, p_{t+1}^{v(k)}$ for $k=1, \ldots, K$ and quality levels $\alpha_{1}, \ldots, \alpha_{K}$, and given equilibrium inequalities ensuring that each car model has positive demand (see the discussion at the end of this section), we find $K$ cutoff values, $\tilde{\theta}_{t}^{1}, \ldots, \tilde{\theta}_{t}^{K}$, such that

$$
\bar{\theta} \geq \tilde{\theta}_{t}^{1} \geq \tilde{\theta}_{t}^{2} \geq \tilde{\theta}_{t}^{3} \geq \ldots \geq \tilde{\theta}_{t}^{K} \geq 0
$$

and all consumers with preference parameter $\theta \in\left[\tilde{\theta}_{t}^{1}, \bar{\theta}\right]$ consume car 1 , all consumers with preference parameter $\theta \in\left[\tilde{\theta}_{t}^{2}, \tilde{\theta}_{t}^{1}\right]$ consume car 2, etc. Finally, all consumers with preference parameter

\footnotetext{
${ }^{7}$ Because we normalize $\alpha_{K+1}$ to zero, $p_{t}^{K+1}=0 \forall t$.

${ }^{8}$ Allowing for transaction costs would complicate the derivation of the dynamic demand functions, because in that case consumers' utility gains are state dependent, depending on what car was chosen in the previous period: see, for example (Anderson and Ginsburgh, 1994; Porter and Sattler, 1999; Stolyarov, 2002).

${ }^{9}$ The recent empirical literature on the car industry ((Berry, Levinsohn, and Pakes, 1995), for example) has allowed for multiple dimensions of consumer heterogeneity, but there are difficult conceptual and computational issues in extending such models to a dynamic equilibrium framework (cf. (Berry and Pakes, 1999)).
} 
$\theta \in\left[0, \tilde{\theta}_{t}^{K}\right]$ do not consume a car. These cutoff values solve the indifference conditions

$$
\begin{aligned}
\alpha_{k} \tilde{\theta}_{t}^{k}-p_{t}^{k}+\delta p_{t+1}^{v(k)} & =\alpha_{k+1} \tilde{\theta}_{t}^{k}-p_{t}^{k+1}+\delta p_{t+1}^{v(k+1)}, & & \text { for } k=1, \ldots, K-1, \\
\alpha_{k} \tilde{\theta}_{t}^{k}-p_{t}^{k} & =0, & & \text { for } k=K .
\end{aligned}
$$

Then, by letting $x_{t}^{k}$ denote the demand for car $k$ in period $t$, we find that

$$
\begin{aligned}
x_{t}^{1} & =M\left(1-F\left(\tilde{\theta}_{t}^{1}\right)\right)=\frac{M}{\bar{\theta}}\left(\bar{\theta}-\tilde{\theta}_{t}^{1}\right), \\
x_{t}^{k} & =M\left(F\left(\tilde{\theta}_{t}^{k-1}\right)-F\left(\tilde{\theta}_{t}^{k}\right)\right)=\frac{M}{\bar{\theta}}\left(\tilde{\theta}_{t}^{k-1} \tilde{\theta}_{t}^{k}\right), \text { for } k=2, \ldots, K, \\
x_{t}^{K+1} & =M\left(F\left(\tilde{\theta}_{t}^{K}\right)\right)=\frac{M}{\bar{\theta}}\left(\tilde{\theta}_{t}^{K}\right) .
\end{aligned}
$$

Substituting these demand functions recursively in Eq. (6), we can write the $K$ cutoff values as

$$
\tilde{\theta}_{t}^{k}=\bar{\theta}\left(1-\frac{1}{M} \sum_{r=1}^{k} x_{t}^{r}\right), \text { for } k=1, \ldots, K .
$$

Substituting these expressions for the cutoff values into the indifference conditions given in Eq. (5) and we obtain the inverse demand functions for each of the cars sold. In particular, a new car model $i \in \mathcal{L}$ with depreciation schedule $\eta(i), v(\eta(i)), \ldots, v^{T_{i}}(\eta(i))$ has inverse demand function

$$
p_{t}^{\eta(i)}=\bar{\theta}\left(\alpha_{\eta(i)}-\alpha_{\eta(i)+1}\right)\left(1-\frac{1}{M} \sum_{r=1}^{\eta(i)} x_{t}^{r}\right)+\delta p_{t+1}^{v(\eta(i))}+p_{t}^{\eta(i)+1}-\delta p_{t+1}^{v(\eta(i)+1)},
$$

where the prices $p_{t+1}^{v(\eta(i))}, p_{t}^{\eta(i)+1}$ and $p_{t+1}^{v(\eta(i)+1)}$ have analogous expressions. In deriving the demand equations, we assume that the primary and secondary markets are not in excess supply, so that the non-negative price constraints never bind in any market. This assumption, made in order to maintain tractability for our model, rules out the possibility that a firm could choose high production levels to bring a primary or secondary market into excess supply, making the price of a car in this market (and the prices of all cars ranked below it in the quality ladder) equal to zero. ${ }^{10}$

By substituting prices recursively into Eq. (8) we obtain the inverse demand function for new model

\footnotetext{
${ }^{10}$ (Esteban, 2002) showed that, for the durable goods monopoly case, the secondary market will not be in excess supply in equilibrium. The result might not generalize for the more general model presented in this paper.
} 
$i \in \mathcal{L}$ as

$$
\begin{aligned}
p_{t}^{\eta(i)}= & \bar{\theta}\left(\alpha_{\eta(i)}\left(1-\sum_{r=1}^{\eta(i)} \frac{1}{M} x_{t}^{r}\right)-\sum_{r=\eta(i)+1}^{K} \alpha_{r} \frac{1}{M} x_{t}^{r}\right)+ \\
& \bar{\theta} \sum_{h=1}^{T_{i}-1} \delta^{h}\left(\alpha_{v^{h}(\eta(i))}\left(1-\sum_{r=1}^{v^{h}(\eta(i))} \frac{1}{M} x_{t+h}^{r}\right)-\sum_{r=v^{h}(\eta(i))+1}^{K} \alpha_{r} \frac{1}{M} x_{t+h}^{r}\right),
\end{aligned}
$$

which is linear in current and future production levels.

In equilibrium, prices will satisfy the inequalities

$$
\frac{\rho_{t}^{k-1}-\rho_{t}^{k}}{\alpha_{k-1}-\alpha_{k}} \geq \frac{\rho_{t}^{k}-\rho_{t}^{k+1}}{\alpha_{k}-\alpha_{k+1}} \geq \frac{\rho_{t}^{k+1}-\rho_{t}^{k+2}}{\alpha_{k+1}-\alpha_{k+2}} \geq 0, k=2, \ldots, K, \forall t,
$$

which imply that the demand for each car is positive given the assumption that the markets are not in excess supply. For the empirical work, given actual prices, these inequalities function as restrictions on the feasible values that the $\alpha$ parameters can take. Because these restrictions are nonlinear in prices, it is difficult to impose them in estimating the parameters. We do not impose these restrictions in estimation, but rather examine ex-post how many of these inequalities are satisfied for the parameter estimates we obtain.

\section{The producers' dynamic problem}

Having derived the inverse-demand functions for each car transacted, we now turn to the supply side and analyze the dynamic optimization problem faced by producers. The assumption that no market will be in excess supply (i.e., that the price given in Eq. (8) is strictly positive) implies that the quantity demanded will equal the quantity supplied in all markets. Consequently, for each car model $i \in \mathcal{L}$, volumes in the secondary market evolve according to

$$
x_{t+h-1}^{v^{h-1}(\eta(i))} \equiv x_{t}^{\eta(i)}, \quad \text { for } h=2, \ldots, T_{i} .
$$

That is, the current production of model $i, x_{t}^{\eta(i)}$, becomes the supply in secondary market $v(\eta(i))$ during period $t+1$, and becomes the supply in secondary market $v^{2}(\eta(i))$ during period $t+2$, and so on. ${ }^{11}$

\footnotetext{
${ }^{11}$ Our model can accommodate exogenous depletion of the stocks by setting $x_{t+h-1}^{v^{h}(\eta(i))} \equiv \delta_{i, h} x_{t}^{\eta(i)}$, where $\delta_{i, h} \in[0,1]$ is the exogenous probability that car $i$ be scrapped at age $h$. This is done in our empirical work below.
} 
Let $\boldsymbol{y}_{t}$ denote the vector of all cars-in-use (both new and used) in period $t$, defined as ${ }^{12}$

$$
\boldsymbol{y}_{t} \equiv\left[1, x_{t}^{1}, \ldots, x_{t}^{K}\right]^{\prime} .
$$

Let $\boldsymbol{d}_{t}$ denote the $L$-dimensional vector of all new cars $(L \times 1)$ produced in period $t$ as

$$
\boldsymbol{d}_{t} \equiv\left[x_{t}^{\eta(1)}, x_{t}^{\eta(2)}, \ldots, x_{t}^{\eta(L)}\right]^{\prime}
$$

Then, given these definitions, the law of motion of the cars-in-use vector $\boldsymbol{y}_{t}$ is

$$
\boldsymbol{y}_{t}=\boldsymbol{A} \boldsymbol{y}_{t-1}+\boldsymbol{B} \boldsymbol{d}_{t}
$$

where $\boldsymbol{B}$ and $\boldsymbol{A}$ are matrices which, respectively, place new car models in the quality ladder and shift cars within the quality ladder as they age. Specifically, $\boldsymbol{B}$ is a $(K+1) \times L$ matrix with entries

$$
\boldsymbol{B}(k+1, i) \equiv\left\{\begin{array}{ll}
1, & \text { if } \eta(i)=k \\
0, & \text { otherwise }
\end{array} \quad \text { for } i=1, \ldots, L, k=1, \ldots, K,\right.
$$

and $\boldsymbol{A}$ is a $(K+1) \times(K+1)$ matrix with entries ${ }^{13}$

$$
\boldsymbol{A}\left(k^{\prime}+1, k+1\right) \equiv\left\{\begin{array}{ll}
1, & \text { if } k^{\prime}=k=0 \\
1, & \text { if } v(k)=k^{\prime} \\
0, & \text { otherwise }
\end{array} \quad \text { for } k, k^{\prime}=1, \ldots, K\right.
$$

Next, we let $C_{j}\left(x_{t}^{\eta(i)} ; \forall i \in \mathcal{L}_{j}\right)$ denote the total cost function for firm $j$. We assume the total costs of production are quadratic in output and independent across car models, so that

$$
C_{j}\left(x_{t}^{\eta(i)} ; \forall i \in \mathcal{L}_{j}\right)=\sum_{i \in \mathcal{L}_{j}}\left[\beta_{0 i}+\beta_{1 i} x_{t}^{\eta(i)}+\beta_{2 i}\left(x_{t}^{\eta(i)}\right)^{2}\right] .
$$

Given the linear inverse demand functions, and quadratic cost function, the period $t$ profit function for firm $j$ will be a quadratic function in current and future production:

$$
\begin{aligned}
\pi_{t}^{j} & =\sum_{i \in \mathcal{L}_{j}} p_{t}^{\eta(i)} \cdot x_{t}^{\eta(i)}-C_{j}\left(x_{t}^{\eta(i)} ; \forall i \in \mathcal{L}_{j}\right) \\
& =\sum_{i \in \mathcal{L}_{j}}\left[\sum_{h=1}^{T_{i}} \delta^{h-1} \boldsymbol{y}_{t+h-1}^{\prime} \boldsymbol{R}_{\omega(i, h)} \boldsymbol{y}_{t}\right]-\boldsymbol{y}_{t}^{\prime} \boldsymbol{C}_{j} \boldsymbol{y}_{t} \\
& \equiv \sum_{i \in \mathcal{L}_{j}} \Pi^{i}\left(\boldsymbol{y}_{t+\tau} ; \tau=0, \ldots, T_{i}-1\right),
\end{aligned}
$$

\footnotetext{
${ }^{12} \mathrm{As}$ is standard in the matrix formulation of linear-quadratic problems, we set the first entry of $\boldsymbol{y}_{t}$ equal to 1 identically across all $t$.

${ }^{13}$ The first entry in $\boldsymbol{A}$ is a one, to be consistent with the first entry in the $\boldsymbol{y}_{t}$ vector.
} 
where (i) $\boldsymbol{C}_{j}$ is the $(K+1) \times(K+1)$ matrix of cost function coefficients for firm $j$; and (ii) the matrices $\boldsymbol{R}_{1}, \ldots, \boldsymbol{R}_{K}$ contain the linear coefficients from the inverse demand functions for cars $k=1, \ldots, K$, respectively, in Eq. (9). Specifically, for each car model $i \in \mathcal{L}, \boldsymbol{R}_{\omega(i, h)}$, for $h=1, \ldots, T_{i}$, are $(K+1) \times(K+1)$ matrices with zeros everywhere except for the $\eta(i)$-th column (the column that corresponds to the quality ranking of a new model $i$ ). This column is set to

$$
[\alpha_{\omega(i, h)} \bar{\theta}, \underbrace{-\alpha_{\omega(i, h)} \frac{\bar{\theta}}{M}, \ldots,-\alpha_{\omega(i, h)} \frac{\bar{\theta}}{M}}_{\text {entries } 2, \ldots, \omega(i, h)}, \underbrace{-\alpha_{\omega(i, h)} \frac{\bar{\theta}}{M},-\alpha_{\omega(i, h)+1} \frac{\bar{\theta}}{M}, \ldots,-\alpha_{K} \frac{\bar{\theta}}{M}}_{\text {entries } \omega(i, h)+1, \ldots, K+1}]^{\prime} .
$$

From the expression for $\pi_{t}^{j}$ in Eq. (17), we see that firm $j$ 's profits in period $t$ depend not only on its own current, past, and future production, but also on the current, past, and future production of all its rivals. The latter dependence arises only in a durable-goods oligopoly. In this dynamic setting, therefore, firms' production strategies at a given period $t$ can become unwieldy because they can depend on the entire production history of all firms prior to period $t$. An appealing and natural assumption here is to allow firms' production choices today to depend only on cars produced in the past which still actively trade in secondary markets today.

This corresponds to a standard Markov assumption that firms' strategies only depend on past variables which affect current (period $t$ ) profits. ${ }^{14}$ In our dynamic setting, these "payoff-relevant" variables are $\boldsymbol{A} \boldsymbol{y}_{t-1}$, the vector of the stock of cars produced prior to period $t$ which are still actively traded in secondary markets. ${ }^{15}$ Hence, we focus on production strategies of the form

$$
x_{t}^{\eta(i)}=g_{i}\left(\boldsymbol{A} \boldsymbol{y}_{t-1}\right), \forall i \in \mathcal{L}_{j}, \forall j \in \mathcal{N}
$$

In order to obtain the linear-quadratic specification, we assume that production rules are linear in the state vector, so that

$$
x_{t}^{\eta(i)}=\boldsymbol{g}_{i} \cdot \boldsymbol{A} \boldsymbol{y}_{t-1},
$$

where $\boldsymbol{g}_{i}$ is a $K+1$-vector of linear coefficients.

We can then write each firm's maximization problem as a dynamic programming problem with state variable $A \boldsymbol{y}_{t-1}$. The Bellman equation for this problem is:

$$
V_{j}\left(\boldsymbol{A} \boldsymbol{y}_{t-1}\right)=\max _{x_{t}^{\eta(i)}, \forall i \in \mathcal{L}_{j}} \sum_{i \in \mathcal{L}_{j}} \Pi^{i}\left(\boldsymbol{y}_{t}, \boldsymbol{y}_{t+1}, \ldots, \boldsymbol{y}_{t+T_{i}-1}\right)+\delta V_{j}\left(\boldsymbol{A} \boldsymbol{y}_{t}\right)
$$

\footnotetext{
${ }^{14}$ See (Fudenberg and Tirole, 1991) for a discussion.

${ }^{15}$ Note that the state vector cannot be $\boldsymbol{y}_{t-1}$, because this vector contains $x_{t-1}^{v^{T_{i}-1}(\eta(i))}$, the cars which have died between periods $t-1$ and period $t$, which cannot affect period $t$ profits directly.
} 
Given our assumptions so far, the value function $V_{j}(\cdot)$ will be a quadratic function of the state vector. Subsequently, each firm's dynamic programming problem in Eq. (19) is a linear-quadratic problem in the state vector $\boldsymbol{A} \boldsymbol{y}_{t-1}:{ }^{16}$

$$
\boldsymbol{y}_{t-1}^{\prime} \boldsymbol{A}^{\prime} \boldsymbol{S}_{j} \boldsymbol{A} \boldsymbol{y}_{t-1}=\max _{x_{t}^{\eta(i)}, \forall i \in \mathcal{L}_{j}}\left\{\sum_{i \in \mathcal{L}_{j}}\left[\sum_{h=1}^{T_{i}} \delta^{h-1} \boldsymbol{y}_{t+h-1}^{\prime} \boldsymbol{R}_{\omega(i, h)} \boldsymbol{y}_{t}\right]\right\}-\boldsymbol{y}_{t}^{\prime} \boldsymbol{C}_{j} \boldsymbol{y}_{t}+\delta \boldsymbol{y}_{t}^{\prime} \boldsymbol{A}^{\prime} \boldsymbol{S}_{j} \boldsymbol{A} \boldsymbol{y}_{t}
$$

where, for $h=1, \ldots, T_{i}-1$,

$$
\boldsymbol{y}_{t+h}=\boldsymbol{A} \boldsymbol{y}_{t+h-1}+\boldsymbol{B} \boldsymbol{d}_{t+h}
$$

and

$$
\boldsymbol{d}_{t+h}=\boldsymbol{G} \boldsymbol{A} \boldsymbol{y}_{t+h-1}
$$

In these equations, (i) $\boldsymbol{S}_{j}$ is the $(K+1) \times(K+1)$ matrix of coefficients in firm $j$ 's value function, which is quadratic in $\boldsymbol{A} \boldsymbol{y}_{t}$; and (ii) $\boldsymbol{G}=\left[\boldsymbol{g}_{1}, \ldots, \boldsymbol{g}_{L}\right]^{\prime}$ is a matrix containing the coefficients of the linear equilibrium production rules. Hence, for our linear-quadratic dynamic durable-goods oligopoly game, a Markov perfect equilibrium specifies linear decision rules, summarized by the coefficient matrix $\boldsymbol{G}$, and value functions $V_{j}(\cdot)$, as summarized by the matrix $\boldsymbol{S}_{j}$, for $j \in \mathcal{N}$, such that these solve the dynamic programming problems given by Eqs. (20)-(22).

We note that the production strategies that solve the dynamic programming problem in Eq. (19) are time consistent, in the sense that firms correctly anticipate their own future optimal behavior. Time-consistency is equivalent to the principle of optimality for dynamic programming problems. With our payoff function, firms can obtain a higher discounted profit stream by committing (at time t) to future production paths $\left\{x_{t+\tau}^{\eta(i)}, \forall i \in \mathcal{L}_{j}\right\}_{\tau=0}^{\infty}$ that solve

$$
\max _{\left\{x_{t}^{\eta(i)}, i \in \mathcal{L}_{j}\right\}_{t=0}^{\infty}} \sum_{\tau=0}^{\infty} \sum_{i \in \mathcal{L}_{j}} \delta^{t} \pi_{t+\tau}^{j}
$$

subject to the law-of-motion in Eq. (21). The solution to this problem, however, would be timeinconsistent since, once period $t$ passes, the firm no longer internalizes the effect of period $t+1$ production on her period $t$ profits and will choose to revise its production plan.

In the appendix, we complete the derivation of the linear-quadratic Markov perfect equilibrium for our problem, and also describe how we compute it using a value function iteration procedure.

\footnotetext{
${ }^{16}$ (Judd, 1996) uses a similar approach to derive a linear-quadratic dynamic oligopoly model.
} 
For our empirical work below, we extend the linear-quadratic model to accommodate imported automobiles, which are assumed to be exogenously produced from the Big 3 manufacturers' point of view. Details of this extension are given in the appendix.

\section{Illustrative simulations from simplified linear-quadratic model}

In our empirical work below, we will use time series on automobiles prices (both new and used) and quantities over a twenty-year period to estimate the model parameters, using the linear inverse demand and supply relations (Eqs. (9) and (A1)) as estimating equations. In order to gain some intuition for the variation in the data identifying the model parameters, we consider a simple version of the model, in which a monopolist produces new cars which last for two periods. We normalize the quality of a new car to 1 , and let $\alpha(<1)$ denote the quality of a used automobile, where $\alpha$ also measures the substitutability between a new and a used car. We assume the marginal cost of production is constant. (For more detail on the workings of this model and proofs for these results, see (Esteban, 2002).)

For this more tractable set-up, the inverse demand function given in Eq. (9), which relates the price of a new car with current, lagged, and future production, is given by

$$
p_{t}^{N}=(1-\alpha)\left(1-x_{t}\right)+\alpha\left(1-x_{t}-x_{t-1}\right)+\delta \alpha\left(1-\left(a_{0}+a_{1} x_{t}\right)-x_{t}\right),
$$

and the supply equilibrium decision in Eq. (A1) is

$$
x_{t+1}=a_{0}+a_{1} x_{t}
$$

where the slope coefficient $a_{1}$ captures the degree of serial dependence in the production process. The coefficients in these equations (and thus the size and magnitude of the co-movements among prices and current and lagged output) depend on the values of $\alpha, c$, and $\delta$.

We first consider the effects of different values of $\alpha$. As the top left graph in Figure 1 shows, larger values of $\alpha$, which imply more substitutability between primary and secondary markets, increase both new and used prices, and decrease new car production. Furthermore, the top right graph in Figure 1 shows that increases in $\alpha$ raise the magnitude of $a_{1}$ (which is negative in value), so that current production becomes more sensitive to previous production. The bottom graph shows that increases in $\alpha$ decrease the coefficients for current and lagged production (making them larger in magnitude since these coefficients are negative) in the inverse demand equation. Hence, as $\alpha$ increases, the (negative) association between past production and current price becomes relatively stronger. 
Next, we look at the effects of different values of the marginal cost parameter $c$. Not surprisingly, larger values of $c$ lower new car production, and increase primary and secondary market prices. However, Figure 2 shows that changes to $c$ leave the $a_{1}$ coefficient unchanged, which implies that these changes do not affect the serial dependence of new car production across time, and thus do not affect the co-movements of prices. These results suggest that levels of prices and output identify the cost parameters, while across-time dependence in these variables and their levels help identify the $\alpha$ parameters. Along the dynamic equilibrium path of the deterministic model which we have described up to now, prices and output only vary across time during the convergence to the steady-state; once the steady-state is reached, prices and output remain constant thereafter. For the purposes of our empirical work, we allow for exogenous shocks to firms' marginal costs which drive movements in prices and output over time.

\section{Empirical illustration: the automobile market 1971-1990}

In this section, we describe our empirical implementation of the model presented above, using annual data for the automobile industry from 1971 to 1990, inclusive. For new cars, we use data on list prices and quantities collected from past issues of Ward's Automotive Yearbook. ${ }^{17}$ We manually compiled time series on secondary market retail prices at the model-vintage level from back issues of the Kelley Blue Book (western US edition). ${ }^{18}$

We aggregate each domestic (US) manufacturer's car production up to the segment level, and assume that each manufacturer produces three "composite" goods each period. By modeling competition between cars at the (manufacturer-segment) level, we are able to abstract away from issues regarding the entry and exit of individual car models, which our model does not address; furthermore, it reduces the dimensionality of the state space of the dynamic programming problem, which is convenient for computational reasons. Specifically, consumers choose from the following ten composite cars each period:

Chrysler: Subcompact (SC), Compact (C), Mid/Full-size (MF)

Ford: $\mathrm{SC}, \mathrm{C}, \mathrm{MF}$

GM: SC, C, MF

Import $^{19}$

\footnotetext{
${ }^{17}$ This is the same dataset employed in (Berry, Levinsohn, and Pakes, 1999).

${ }^{18}$ We thank Bruce Hamilton for providing these old issues.

${ }^{19} \mathrm{We}$ do not break down imports into additional categories, because during the sample period, most of the imported automobiles were in the subcompact segment.
} 
The Kelly Blue Book contains used car prices up to seven-year old vintages. For this reason, we assume that cars are available in seven vintages (new, one-year old, two-year old, ..., six-year old). Furthermore, we assume that owners of six-year old cars scrap their cars at the end of the period and obtain a "scrappage value" equal to the price of a seven-year old model car.

Since the stock of used automobiles decreases significantly over a seven-year life span, we assume that a certain proportion of cars "die" exogenously over time, due to accidents, mechanical failures, etc. Let $\zeta_{i}$ denote the proportion of vintage $i$ cars which die (i.e., $1-\zeta_{i}$ denotes the survival rate of vintage $i$ cars). In our work, we take $\zeta_{1}=\zeta_{2}=0, \zeta_{3}=0.025, \zeta_{4}=0.042, \zeta_{5}=0.065, \zeta_{6}=$ 0.101 . For data availability reasons, we assume that these survival rates are identical across all car models. ${ }^{20}$

In the interests of space, summary statistics for the prices and output of the model-years are not included here, but we summarize some salient characteristics. ${ }^{21}$ Across years and models, prices for older vintages are monotonically lower, as we would expect. Some car models - especially the Chrysler models - experienced declining new production: the amount of new production fell sharply between the mid-1960s (the years for which we initialized the used car stocks for 1970, our initial sample year) and 1990 (the end of our sample period). Hence, for these car models, the stocks of used vintages can exceed new production in most years of the sample, resulting in higher (across-year) average stocks for used vintages than for new production. In addition, there are missing values for some prices, even during years where the quantity of the model-year is not equal to zero. This appears to be due mainly to irregularities in how the Kelly Blue Book reported used car prices: in some years, certain models or vintages were simply not included in the book. Below, we describe how we accommodate these missing prices econometrically. Additional details on the construction of the data variables are given in the appendix.

In each year, then, there are 70 (=10 composites*7 vintages) model-years in consumers' choice sets (in addition to the outside good of no-purchase). Given this large number, we parameterize the $\alpha$ 's as log-linear functions of model year characteristics (similar to (Bresnahan, 1981)). The empirical results below employ the following parameterization:

$$
\alpha_{k}=\exp \left(\mathbf{z}^{\prime} \Gamma\right)
$$

\footnotetext{
${ }^{20}$ These values were derived using data from the Polk Corporation. We thank Darrel Cohen for providing this data; see (Cohen and Greenspan, 1996) for more details on these data.

${ }^{21}$ Interested readers can find a table of summary statistics online, at www. econ. jhu . edu/people/shum/res.html.
} 
where

$$
\begin{aligned}
\mathbf{z}^{\prime} \Gamma= & \gamma_{1} * C H R_{k}+\gamma_{2} * F O R D_{k}+\gamma_{3} * G M_{k}+\gamma_{4} * I M P_{k} \\
& +\left(\gamma_{5} * C_{k}+\gamma_{6} * M F_{k}+\gamma_{7} * S C_{k}\right) *\left(1-I M P_{k}\right) \\
& +\left(\gamma_{8} * C H R_{k}+\gamma_{9} * F O R D_{k}+\gamma_{10} * G M_{k}+\gamma_{11} * I M P_{k}\right) * A G E_{k} \\
& +\left(\gamma_{12} * C_{k}+\gamma_{13} * M F_{k}+\gamma_{14} * S C_{k}\right) *\left(1-I M P_{k}\right) * A G E_{k} \\
& +\gamma_{15} * \mathbf{1}(1979 \leq y r \leq 1982) * I M P_{k}+\gamma_{16} * \mathbf{1}(1983 \leq y r \leq 1986) * I M P_{k} \\
& +\gamma_{17} * \mathbf{1}(1987 \leq y r \leq 1990) * I M P_{k} .
\end{aligned}
$$

In the above, $C H R, F O R D, G M$ and $I M P$ are dummy variables for whether model-year $k$ is a Chrysler, Ford, GM, or imported car, and $S C, C$, and $M F$ are dummy variables for whether it is a subcompact, compact, or mid/full-size car. Note that we do not distinguish between different sizes of imported cars, because most imports during the sample period were subcompacts. $A G E_{k}$ denotes the age of model-year $k$, with $A G E_{k}=0$ for new cars. Finally, we also allow the quality of imported cars to change over time, to accommodate the possibility that foreign producers have improved the quality of their offerings over time, as captured by the coefficients $\gamma_{15}-\gamma_{17}$. We allowed the $\alpha$ 's for the imports to vary for each four-year block in our sample period (but we assumed that the import $\alpha$ 's were constant from 1971-78, because there were relatively low import volumes during these years). ${ }^{22}$

\section{Empirical model}

Although the important demand and supply relations in this market are given by linear equations (Eqs. (8) and (A1)), least-squares estimation of the reduced-form equations will not allow us to recover easily the structural parameters, which are implicit functions of the reduced-form regression coefficients. For this reason, we undertake direct structural estimation of the model parameters via a nested Generalized Method of Moments (GMM) procedure where a value iteration procedure to compute the equilibrium production rules is nested inside an outer loop which searches over parameter values matching the predicted population moments of the data-generating process (which are functions of the parameters) to their sample counterparts. In the rest of this section, we discuss the derivation of these moment conditions.

Up to this point, we have not introduced structural errors - factors observed by the agents in the model but unobserved by the econometrician — into the model. An important property of linear-

\footnotetext{
${ }^{22} \mathrm{We}$ also attempted to allow the effects of size to vary across years by estimating separate coefficients for $C_{k}, S C_{k}$ and $M F_{k}$ for the years 1981-1990. However, in our estimation, these parameters did not move at all from their starting values, indicating that they were not well-identified.
} 
quadratic problems is the certainty equivalence property (cf. (Sargent, 1987)), which implies that the equilibrium decision rules derived above are unchanged if we introduce additive shocks to demand or/and production costs. Therefore, we introduce shocks to firms' cost of production, so that the total variable cost of producing $x_{t}^{\eta(i)}$ is $x_{t}^{\eta(i)}\left(\beta_{1 i}+\beta_{2 i} x_{t}^{\eta(i)}+\epsilon_{i t}\right)$. If we assume that the vector of cost shocks $\epsilon_{t} \equiv\left[\epsilon_{1 t}, \ldots, \epsilon_{L t}\right]^{\prime}$ is a zero-mean vector which is i.i.d. across all periods $t$, then the certainty-equivalence property of linear-quadratic games implies that the stochastic vector of optimal production rules in the presence of cost shocks is

$$
\boldsymbol{d}_{t}=\boldsymbol{G} \boldsymbol{A} \boldsymbol{y}_{t-1}+\boldsymbol{w}_{t}
$$

where $\boldsymbol{w}_{t}$ is a vector of linear functions of the cost shocks $\epsilon_{1 t}, \ldots, \epsilon_{L t}$ with zero mean and $G$ is the equilibrium decision rule coefficients derived in Eq. (A2) ${ }^{23}$ Therefore, the decision rules with cost shocks (24) are equal to the decision rules without cost shocks (in Eq. (22)) plus an additive component which is stochastic from the econometrician's point of view, but with mean zero (and, furthermore, uncorrelated with $\boldsymbol{y}_{t-1}$ ) and independent over time.

In the presence of cost shocks, the linear inverse demand functions in period $t$ becomes

$$
p_{t}^{\eta(i)}=\left(\alpha_{\eta(i)}-\alpha_{\eta(i)+1}\right)\left(1-\frac{1}{M} \sum_{r=1}^{\eta(i)} x_{t}^{r}\right)+\delta E\left[p_{t+1}^{v(\eta(i))} \mid \Omega_{t}\right]+p_{t}^{\eta(i)+1}-\delta E\left[p_{t+1}^{v(\eta(i)+1)} \mid \Omega_{t}\right],
$$

where $\Omega_{t}$ denotes consumers' information sets as of period $t$. This is the stochastic analogue of Eq. (8) above. Given the linearity of this equation, and our stochastic assumptions regarding the cost shocks, we derive that

$E\left[p_{t}^{\eta(i)}-\left(\alpha_{\eta(i)}-\alpha_{\eta(i)+1}\right) F^{-1}\left(1-\frac{1}{M} \sum_{r=1}^{\eta(i)} x_{t}^{r}\right)+\delta p_{t+1}^{v(\eta(i))}+p_{t}^{\eta(i)+1}-\delta p_{t+1}^{v(\eta(i)+1)} \mid \Omega_{t}\right]=0$.

Thus, Eqs. (24) and (26) are the main estimating equations for our model. ${ }^{24}$

Details The structural parameters of the model are (i) $\alpha_{1}, \ldots, \alpha_{K}$, the qualities of the competing cars; and (ii) $\beta_{1 i}, \beta_{2 i}, i=1, \ldots, L$, the marginal cost parameters for the new cars. As is usual in

\footnotetext{
${ }^{23}$ The certainty equivalence property also implies that stochastic production rules (24) will still hold if we also allowed for additive i.i.d. demand shocks in the inverse demand functions (Eqs. (6)). However, we do not do this because allowing demand shocks would rule out the use of current market shares and prices as instruments (see below).

${ }^{24}$ In the presence of cost shocks, the inequalities in Eqs. (10) hold for the expected rental prices $p_{t}^{k}-E_{t} \delta p_{t+1}^{v(k)}$.
} 
empirical dynamic models, the discount factor $\delta$ is not estimated, but rather fixed (at 0.95 , in our case). Furthermore, the upper bound of the consumer heterogeneity distribution, $\bar{\theta}$, cannot be identified separately from the scale of the $\alpha$ 's, and is fixed equal at 3 in the econometric implementation.

For the supply side, the estimating equations are the equilibrium production rules linking current production of new cars to stock of used cars in the market (Eqs. (24)). The sample moment conditions are

$$
\frac{1}{T} \sum_{t}\left[\boldsymbol{d}_{t}-(\boldsymbol{G A}) \boldsymbol{y}_{t-1}\right] * \boldsymbol{y}_{t-1}
$$

where past production $\boldsymbol{y}_{t-1}$ is an appropriate instrument orthogonal to the error term $\boldsymbol{w}_{t}$ in Eq. (24).

The population moment restrictions for the demand side are given in Eq. (26). Let $z_{t}$ denotes a vector of instruments, which are elements of $\Omega_{t}$, the information set of consumers for period $t$. In our specifications, $\boldsymbol{z}_{t}$ consists of the constant 1 , current and lagged market shares, and current and lagged prices as instruments. Therefore, the sample analog of the demand-side moment restrictions for production of car $\eta(i)$ take the form

$$
\frac{1}{T} \sum_{t=1}^{T}\left[p_{t}^{\eta(i)}-\left(\alpha_{\eta(i)}-\alpha_{\eta(i)+1}\right)\left(1-\frac{1}{M} \sum_{r=1}^{\eta(i)} x_{t}^{r}\right)+\delta p_{t+1}^{v(\eta(i))}+p_{t}^{\eta(i)+1}-\delta p_{t+1}^{v(\eta(i)+1)}\right] * \boldsymbol{z}_{t}
$$

where the sample moment conditions are evaluated, for each period $t$, at the realized prices in periods $t$ and $t+1$. We obtain estimates of the structural parameters $\boldsymbol{\psi}$ via GMM, by minimizing a quadratic form in the sample moment conditions given in Eqs. (28) and (27). ${ }^{25}$

We accommodate the missing prices in a straghtforward manner. The missing prices do not affect the supply-side estimating equations (27), but we amend the demand side estimating equation (28) as

$\frac{1}{T} \sum_{t=1}^{T}\left[p_{t}^{\eta(i)}-\left(\alpha_{\eta(i)}-\alpha_{\eta(i)+1}\right)\left(1-\frac{1}{M} \sum_{r=1}^{\eta(i)} x_{t}^{r}\right)+\delta p_{t+1}^{v(\eta(i))}+p_{t}^{\eta(i)+1}-\delta p_{t+1}^{v(\eta(i)+1)}\right] * \boldsymbol{z}_{t} * m_{k t}$,

where $m_{i t}$ be an indicator variable which equals one if none of the prices $p_{t}^{\eta(i)}, p_{t+1}^{v(\eta(i))}, p_{t}^{\eta(i)+1}$, and $p_{t+1}^{v(\eta(i)+1)}$ are missing. We assume that prices are missing at random, in the sense that this amended sample analog converges to zero (at the true parameter values), similarly to the unamended sample analog in Eq. (28).

\footnotetext{
${ }^{25}$ For the results reported in this paper, we employ a diagonal weighting matrix, in which each moment condition is weighted by the inverse of its marginal sample variance.
} 


\section{Empirical results}

Before discussing the results, we reiterate that our model is stylized, and simplifies many aspects of the automobile market. Indeed, at the reported parameter values, only half (50.8\%) of the equilibrium inequalities (in Eq. (10)) are satisfied, which captures the difficulty of the theoretical model in generating price patterns similar to those observed in the data. ${ }^{26}$ Thus, we feel that a primary value of this empirical exercise is to demonstrate the feasibility of estimating a dynamic durable goods model for this industry.

The quality ladder parameters (the $\alpha$ 's) are reasonably precisely estimated. For convenience, rather than reporting the individual estimates of each $\alpha,{ }^{27}$ we have graphed these $\alpha$ estimates for the nine car models produced by the Big 3 companies, as well as the imports, in Figure 3. We see that, generally, car size is positively related to quality, with mid-size cars offering the highest quality, followed by compact and subcompact cars. Brand effects are prominent, with Ford and GM cars offering higher quality than Chrysler cars. The extent of depreciation also differs across brands, with Ford cars depreciating relatively slowly, and Chrysler cars depreciating relatively quickly.

As illustrated in the bottom graph of Figure 3, our results also suggest that the quality of imports improved over time. This supports anecdotal evidence that importers (notably Japanese manufacturers) improved the quality of their cars in response to the import quotas that the US levied against them. However, this improvement was not monotonic; the import $\alpha$ 's for the years 1983-1986 lie below those for 1979-1982.

To gauge how well our model fits the data, we simulated the model using our parameter estimates, and present the steady-state output and price levels for each of the nine domestic composites in Table 2. A comparison of the actual to simulated values shows that the simulated production levels correspond reasonably closely to the actual production levels. However, the simulated prices fit poorly, and are generally higher than the averages prices in the data: for example, the actual average price of a Ford MF model is $\$ 9,958$, but the analogous value is $\$ 14,609$ in the simulated steady state of the dynamic model.

Furthermore, we also simulated the equilibrium profits for each car model on a year-by-year basis, to see how they change over time. These results (not reported for brevity's sake) indicate that the profits for all nine domestic car models fell over the twenty year period, which is perhaps not surprising given that the Big 3 new sales share fell over this time period, relative to imports. However, these simulations also show that the profits of the Chrysler models fell most sharply (by $8.4 \%, 11.3 \%$, and

\footnotetext{
${ }^{26}$ In calculating the inequalities, we assumed that $E_{t} \delta p_{t+1}^{v(k)}=p_{t}^{v(k)}$, which holds in steady-state.

${ }^{27}$ These estimates and standard errors are available on the web at www. econ. jhu . edu/people/shum/res. html.
} 
$10.8 \%$, respectively, for subcompact, compact, and midsize/full cars), followed by Ford and then GM. While this could be consistent with the historical fact that Chrysler was a failing company for much of the 1970s, it also reflects the decreasing trend in the market share of Chrysler cars during the sample period.

The cost function parameters (reported in Table 1) are not estimated precisely. One reason for this may be the relatively short $(T=20)$ time series for production quantities in the dataset. In the third column of Table 3, we report the markups corresponding to our marginal cost parameter estimates. The markups are noticeably small, with all of them lying below 6\%. This is perhaps the most puzzling of the results that we obtained, because these markup estimates are much lower than the markup estimates derived in previous empirical work.

One possible factor in the low markups is that we assume that consumers face no transactions costs, which increases transactions in all markets. While it is beyond the scope of this paper to consider a model in which consumers face transactions costs in buying used cars, we performed some simulations to gauge its potential effects by reducing the population scaling parameter $M$ which, as is seen from Eq. (6), shifts down the demand functions faced by the firm, which might approximate (imperfectly) some of the implications of accommodating transaction costs, which is to reduce the size of the consumer population actively trading in car markets.

We simulated the model, using the estimation results discussed above, for counterfactual population values equal to $75 \%, 50 \%$, and $25 \%$ of the actual average in-sample population value (of 73 million households). The counterfactual simulated markups are reported in Table 3 . The results indicate that markups would increase: for example, for GM, markups would increase to $9.0 \%, 8.7 \%$ and $8.2 \%$ for the subcompact, compact, and midsize/full models, respectively, if the population were halved. While this increase in markup appears uniform across all car models, it is smallest in magnitude for the Chrysler car models. These simulations suggest that the predicted markups may appear more reasonable if the effective population were reduced, which can imply that by not accommodating transactions costs, we are overstating the effective consumer population in our econometric model.

Counterfactual experiments Since an important difference between this paper and previous empirical work on the automobile industry is the explicit modeling of the intertemporal links between the primary and secondary markets, we conclude the paper with counterfactual simulations which quantify the effects of the secondary market on new car production. In these counterfactuals, we simulated the effects of a temporary elimination of the secondary market by computing the change in production (relative to the steady-state production levels given in Table 2 above) if producers faced empty secondary markets for one period. This elimination of the secondary market lasts only 
one period because, in subsequent periods, the secondary markets will once again be active as new cars produced today age. The extent to which output adjusts in the period in which the stock is eliminated provides a measure of how much the secondary market affects the primary market after accounting for the intertemporal link between primary and secondary markets, which stems directly from the dynamic model derived in this paper since it is measured by the constant coefficient in Eq. (A2).

In Table 4, we report the simulation results broken down by manufacturer, market segment and total primary market. As we would expect, we find that the elimination of the secondary market would lead firms to increase output, although market shares for each firm and segment show only small changes. The disaggregated results show that the temporary disappearance of the secondary market would increase Chrysler's total production by $20.11 \%$, which is twice the corresponding increases for Ford $(10.13 \%)$ and GM (10.47\%). One possible reason for this is that we estimate Chrysler's cars to have the lowest quality when new (cf. the top graph in Figure 3), so that these cars would substitute most readily with used cars, and thereby benefit the most from the elimination of the secondary market. (Ford and GM experience smaller changes in output.) A similar effect appears when percentage changes are aggregated by market segment, where we find that the output of cars in the highest-ranked segment (MF) increases more modestly than the outputs of lowerranked segments (C, SC). Overall, we find that aggregate new car production would increase by $12.08 \%$ for the 1987 - 1990 time frame were the secondary market to disappear temporarily.

\section{Conclusions}

In this paper we develop a model of dynamic oligopoly to understand the intertemporal links which arise from durability of the product and its trade in secondary markets. We use a tractable linearquadratic specification of the model to obtain estimates of the structural parameters and calculate each producer's equilibrium decision rule. While the empirical model is stylized, it represents (as far as we are aware) a first attempt at structural estimation of a dynamic durable goods oligopoly model for the automobile industry.

While the linear-quadratic structure has facilitated the modeling of the effects of durability and secondary markets in the automobile industry, we plan to explore alternative models which may allow us to incorporate additional features which have been shown in the existing literature to be important in the automobile industry, such as transaction costs, asymmetric information, and additional consumer heterogeneity. This may also resolve some of the problems in the current estimates. In- 
corporating these features in the context of a dynamic oligopoly model with secondary markets may involve substantial modeling and computational difficulties, which we plan to tackle in future work. 


\section{Appendix}

The appendix consists of three sections. In the first section, we provide details on the derivation of the Markov perfect equilibrium of the linear-quadratic game. In the second section, we describe how the model could be extended to accommodate imports, and in the third section, we give details on the construction of the data variables used in estimation.

\section{Detailed derivation of the linear-quadratic Markov perfect equilibrium}

In this section, we complete the derivation of the linear-quadratic Markov-Perfect equilibrium of this problem and derive $G$, the matrix of coefficients for the equilibrium decision rule, as a function of the underlying model parameters. By substituting in Eq. (22) into Eq. (21), we obtain that

$$
\boldsymbol{y}_{t+h}=(\boldsymbol{I}+\boldsymbol{B} \boldsymbol{G}) \boldsymbol{A} \boldsymbol{y}_{t+h-1}
$$

By iterating on this, we can write the law of motion as

$$
\boldsymbol{y}_{t+h}=[(\boldsymbol{I}+\boldsymbol{B} \boldsymbol{G}) \boldsymbol{A}]^{h} \boldsymbol{y}_{t}, \text { for } h=1, \ldots, T_{i}-1
$$

Then, substituting the above into Eq. (20), we rewrite firm $j$ 's dynamic programming problem as

$$
\begin{aligned}
\boldsymbol{y}_{t-1}^{\prime} \boldsymbol{A}^{\prime} \boldsymbol{S}_{j} \boldsymbol{A} \boldsymbol{y}_{t-1} & =\max _{x_{t}^{\eta(i)}, \forall i \in \mathcal{L}_{j}} \boldsymbol{y}_{t}^{\prime}\left\{\left[\sum_{i \in \mathcal{L}_{j}} \sum_{h=1}^{T_{i}}\left(\boldsymbol{A}^{\prime}\right)^{h-1}\left[(\boldsymbol{I}+\boldsymbol{B} \boldsymbol{G})^{\prime}\right]^{h-1} \delta^{h-1} \boldsymbol{R}_{\omega(i, h)}\right]-\boldsymbol{C}_{j}+\delta\left[\boldsymbol{A}^{\prime} \boldsymbol{S}_{j} \boldsymbol{A}\right]\right\} \boldsymbol{y}_{t} \\
& \equiv \max _{x_{t}^{\eta(i)}, \forall i \in \mathcal{L}_{j}} \boldsymbol{y}_{t}^{\prime} \boldsymbol{Q}_{j} \boldsymbol{y}_{t} \equiv \max _{x_{t}^{\eta(i)}, \forall i \in \mathcal{L}_{j}} \frac{1}{2} \boldsymbol{y}_{t}^{\prime}\left(\boldsymbol{Q}_{j}+\boldsymbol{Q}_{j}^{\prime}\right) \boldsymbol{y}_{t} \\
& =\max _{x_{t}^{\eta(i)}, \forall i \in \mathcal{L}_{j}} \frac{1}{2}\left(\boldsymbol{A} \boldsymbol{y}_{t-1}+\boldsymbol{B} \boldsymbol{d}_{t}\right)^{\prime}\left(\boldsymbol{Q}_{j}+\boldsymbol{Q}_{j}^{\prime}\right)\left(\boldsymbol{A} \boldsymbol{y}_{t-1}+\boldsymbol{B} \boldsymbol{d}_{t}\right)
\end{aligned}
$$

The second equality in the second line of the above display is a symmetrization of the quadratic form which leaves the value of the objective function unchanged. Let $\boldsymbol{b}_{i}$ denote the $i$-th column of matrix $\boldsymbol{B}$. Then, the first-order condition for firm $j$ 's new production of model $i \in \mathcal{L}_{j}$ is

$$
\boldsymbol{b}_{i}^{\prime}\left(\boldsymbol{Q}_{j}+\boldsymbol{Q}_{j}^{\prime}\right)\left(\boldsymbol{A} \boldsymbol{y}_{t-1}+\boldsymbol{B} \boldsymbol{d}_{t}\right)=0
$$

Therefore, by stacking the first-order conditions for all of the models $i \in \mathcal{L}_{j}$ produced by firm $j$, we obtain

$$
\boldsymbol{B}_{j}^{\prime}\left(\boldsymbol{Q}_{j}+\boldsymbol{Q}_{j}^{\prime}\right) \boldsymbol{A} \boldsymbol{y}_{t-1}+\boldsymbol{B}_{j}^{\prime}\left(\boldsymbol{Q}_{j}+\boldsymbol{Q}_{j}^{\prime}\right) \boldsymbol{B} \boldsymbol{d}_{t}=0
$$


where the matrix $\boldsymbol{B}_{j}$ denotes the $(K+1) \times L_{j}$ matrix formed by extracting the columns of $\boldsymbol{B}$ corresponding to all the models $i \in \mathcal{L}_{j}$.

Define the matrix $\boldsymbol{W}_{j} \equiv \boldsymbol{B}_{j}^{\prime}\left(\boldsymbol{Q}_{j}+\boldsymbol{Q}_{j}^{\prime}\right)$ for each firm $j$, and $\boldsymbol{W} \equiv\left[\boldsymbol{W}_{1}, \ldots, \boldsymbol{W}_{N}\right]^{\prime}$. We stack the systems of first-order conditions for all $N$ firms as

$$
\boldsymbol{W} \boldsymbol{A} \boldsymbol{y}_{t-1}+\boldsymbol{W} \boldsymbol{B} \boldsymbol{d}_{t}=0
$$

and write the industry-wide system of equilibrium decision rules as

$$
\boldsymbol{d}_{t}=-(\boldsymbol{W} \boldsymbol{B})^{-1}(\boldsymbol{W} \boldsymbol{A}) \boldsymbol{y}_{t-1},
$$

which take the form of the equilibrium decision rule given by Eq. (22), with

$$
\boldsymbol{G} \equiv-(\boldsymbol{W} \boldsymbol{B})^{-1} \boldsymbol{W}
$$

In the present problem, we solve for the Markov-Perfect equilibrium production strategies using a value iteration procedure. We consider a long but finite-horizon version of the game and, starting from the terminal period, solve recursively for each firm's optimal production strategies via backward induction. Specifically, for all firms $j \in \mathcal{N}$, we begin with initial guesses for $\boldsymbol{S}_{j}^{0} \equiv[0], j \in \mathcal{N}$ and $G^{0} \equiv[0]$ for their respective matrices of value function and decision rule coefficients. Using these matrices, we calculate recursively, for $\tau=1,2,3, \ldots$,

$$
\begin{aligned}
\boldsymbol{Q}_{j}^{\tau} & \equiv \boldsymbol{A}^{\prime} \boldsymbol{S}_{j}^{\tau} \boldsymbol{A}, j \in \mathcal{N}, \\
\boldsymbol{W}_{j}^{\tau} & \equiv \boldsymbol{B}_{j}^{\prime}\left(\boldsymbol{Q}_{j}^{\tau}+\boldsymbol{Q}_{j}^{\tau \prime}\right), \\
\boldsymbol{W}^{\tau} & \equiv\left[\boldsymbol{W}_{1}^{\tau}, \ldots, \boldsymbol{W}_{N}^{\tau}\right]^{\prime}, \\
\boldsymbol{G}^{\tau+1} & \equiv\left(\boldsymbol{W}^{\tau} \boldsymbol{B}\right)^{-1} \boldsymbol{W}^{\tau} .
\end{aligned}
$$

In each iteration, we update the coefficient matrix for the value functions via $\boldsymbol{S}_{j}^{\tau+1}=\left\{\left[\sum_{i \in \mathcal{L}_{j}} \sum_{h=1}^{T_{i}}\left(\boldsymbol{A}^{\prime}\right)^{h-1}\left[\left(\boldsymbol{I}+\boldsymbol{B} \boldsymbol{G}^{\tau+1}\right)^{\prime}\right]^{h-1} \delta^{h-1} \boldsymbol{R}_{\omega(i, h)}\right]-\boldsymbol{C}_{j}+\delta\left[\boldsymbol{A}^{\prime} \boldsymbol{S}_{j}^{\tau} \boldsymbol{A}\right]\right\}$, for each $j \in \mathcal{N}$.

We iterate this procedure until the sequence of matrices $\boldsymbol{S}_{j}^{\tau}$ and $\boldsymbol{G}^{\tau}$ converges. The converged values of these matrices are the coefficients of the equilibrium value functions and production rules, respectively. Under certain conditions, there is a unique feedback equilibrium, a sequence of production decision rules and value function coefficients, which converges to a Markov perfect equilibrium of the infinite-horizon game. ${ }^{28}$

\footnotetext{
${ }^{28}$ See (Başar and Olsder, 1982; Kydland, 1975) for more details on these conditions for linear-quadratic games.
} 


\section{Accommodating imports}

In this section, we describe how the linear-quadratic framework presented in the main text can be extended to accommodate imported automobiles. Since the focus of the present paper is on competition amongst the Big 3 American producers from 1971-1990, we assume that the production of imports is an exogenous process. ${ }^{29}$ In each period $t$, all domestic firms observe the quantity of new imported cars supplied to the primary market and choose their optimal level of output. We let $m_{t}$ denote the vector of imports and assume that $m_{t}=m_{t-1}+\epsilon_{t}$, where $\epsilon_{t}$ is i.i.d. across periods with zero mean and variance $\sigma^{2}$. Therefore, from the firms' perspective, the import production process is a random walk, with $E_{t}\left(m_{t+h}\right)=m_{t}$ for all $t$ and $h>0$.

We define $z_{t} \equiv A y_{t-1}+D m_{t}$ to be the state vector in $t$, and $\tilde{z}_{t} \equiv E_{t} z_{t+1}=A y_{t}+D m_{t}$ to be the expected state vector for $t+1$ at $t$. (Thus, the matrix $D$ ranks the vector of imports within the quality ladder, and $m_{t}$ can be recovered from $y_{t}$ by $m_{t}=D^{\prime} y_{t}$.)

We conjecture that the equilibrium decision rule and value function take the form:

$$
x_{t}=G z_{t}
$$

and

$$
E_{t} V\left(z_{t+1}\right)=\tilde{z}_{t}^{\prime} W \tilde{z}_{t}
$$

The law-of-motion for used cars is given by

$$
y_{t}=A y_{t-1}+B x_{t}+D m_{t}=z_{t}+B x_{t}
$$

or

$$
y_{t}=z_{t}+B G z_{t}=(I+B G) z_{t}
$$

after substituting in Eq. (B1).

We define $\Gamma \equiv(I+B G) A$. Then, extending the above equation for future periods and taking the expectation at time $t$, we find that

$$
E_{t} y_{t+k}=\Gamma^{k+1} y_{t-1}+\sum_{i=0}^{k} \Gamma^{i}(I+B G) D m_{t} .
$$

\footnotetext{
${ }^{29}$ However, as noted in the main text, we do allow the quality of the imported automobiles to change over the sample period.
} 
By inspection, the definition of the $\boldsymbol{A}$ and $\boldsymbol{D}$ matrices implies that $A D=[0]$, so that $(I+B G) A D=$ $[0]$. Similarly, $B G D=[0]$. Then, we can write the above equation as

$$
E_{t} y_{t+k}=\Gamma^{k+1} y_{t-1}+D m_{t}
$$

Next, we consider the per-period profit function for a product. From Eq. (20),

$$
\pi_{i}=\sum_{h=1}^{T_{i}} y_{t+h-1}^{\prime} R_{\omega(i, h)} y_{t},
$$

where $y$ for future periods must be written in expectations, $E_{t} y_{t+k}=\Gamma^{k} y_{t}+D m_{t}$. Then, the revenue for product $i$ is

$$
\begin{aligned}
\pi_{i} & =y_{t} \sum_{h=1}^{T_{i}} \Gamma^{h-1^{\prime}} \delta^{h-1} R_{\omega(i, h)} y_{t}+m_{t}^{\prime} D^{\prime}\left(\sum_{h=2}^{T_{i}} \delta^{h-1} R_{\omega(i, h)}\right) y_{t} \\
& =y_{t} \underbrace{\sum_{h=1}^{T_{i}}\left(\Gamma^{h-1} \delta^{h-1^{\prime}} R_{\omega(i, h)}+D D^{\prime}\left(\sum_{h=2}^{T_{i}} \delta^{h-1} R_{\omega(i, h)}\right)\right)}_{\equiv \Upsilon_{i}} y_{t}
\end{aligned}
$$

using $m_{t}=D^{\prime} y_{t}$. To write the profit function, firm $j$ produces car models $i \in \mathcal{L}_{j}$. Thus,

$$
\pi_{j}=y_{t}^{\prime} \underbrace{\left(\sum_{i \in \mathcal{L}_{j}} \Upsilon_{i}-C_{j}\right)}_{\equiv \Upsilon} y_{t}^{\prime} .
$$

Then, by substituting $y_{t}$ for the law of motion above, we find that

$$
\begin{aligned}
\pi_{j} & =\left(A y_{t-1}+B x_{t}+D m_{t}\right)^{\prime}\left(\Upsilon-C_{j}\right)\left(A y_{t-1}+B x_{t}+D m_{t}\right) \\
& =\left(A y_{t-1}+D m_{t}\right)^{\prime}(I+B G)^{\prime} \Upsilon(I+B G)\left(A y_{t-1}+D m_{t}\right)
\end{aligned}
$$

Taking expectations at $t-1$,

$$
E_{t-1} \pi_{j}=\left(A y_{t-1}+D m_{t-1}\right)^{\prime}(I+B G)^{\prime} \Upsilon(I+B G)\left(A y_{t-1}+D m_{t-1}\right)+b \sigma^{2},
$$

where $b$ is a constant and $\sigma^{2}$ is the variance of the import innovation.

We now verify our conjecture for the value function and decision rule. The total discounted profit at $t$ is

$$
\begin{aligned}
& z_{t}^{\prime}(I+B G)^{\prime} \Upsilon_{j}(I+B G) z_{t}+\delta \tilde{z}_{t}^{\prime} W_{j} \tilde{z}_{t}= \\
= & z_{t}^{\prime}(I+B G)^{\prime} \Upsilon_{j}(I+B G) z_{t}+\delta z_{t}^{\prime}(I+B G)^{\prime}\left(A+D D^{\prime}\right)^{\prime} W_{j}\left(A+D D^{\prime}\right)(I+B G) z_{t} .
\end{aligned}
$$


Taking expectations at $t-1$,

$\tilde{z}_{t-1}^{\prime}\left((I+B G)^{\prime} \Upsilon_{j}(I+B G)+\delta(I+B G)^{\prime}\left(A+D D^{\prime}\right)^{\prime} W_{j}\left(A+D D^{\prime}\right)(I+B G)\right) \tilde{z}_{t-1}=\tilde{z}_{t-1}^{\prime} W_{j} \tilde{z}_{t-1}$,

which yields our conjecture in Eq. (B2).

The equilibrium decision rule is verified as follows. From Eq. (B3) and our conjectured decision rule (Eq. (B1)), the firm solves

$$
\max y_{t}^{\prime} \Upsilon_{j} y_{t}+\tilde{z}_{t}^{\prime} W_{j} \tilde{z}_{t},
$$

where $\tilde{z}_{t}=A y_{t}+D m_{t}$. Recall that $m_{t}=D^{\prime} y_{t}$, which implies $\tilde{z}_{t}=A y_{t}+D D^{\prime} y_{t}=\left(A+D D^{\prime}\right) y_{t}$, and allows us to write the problem for the firm as

$$
\max y_{t}^{\prime} \Upsilon_{j} y_{t}+y_{t}^{\prime}\left(A+D D^{\prime}\right)^{\prime} W_{j}\left(A+D D^{\prime}\right) y_{t}=\max y_{t}^{\prime} Q_{j} y_{t}
$$

Then, we follow the same steps as in Appendix 4 to obtain

$$
G=-(W B)^{-1} W
$$

where $W=\left[W_{1}, \ldots, W_{N}\right]^{\prime}$ and $W_{j}=B_{j}^{\prime}\left(Q_{j}+Q_{j}^{\prime}\right)$.

\section{Data appendix}

Here we list additional assumptions made in constructing the dataset used in estimating the model.

The market size $M$ is set equal to the total number of households in the United States. In the empirical work, in order to control for population growth over time, we normalize the market size $M$ to be constant over time, and equal to its value in the first sample year 1971 (in which the number of households was 72.96 million). We correspondingly adjust the quantities in each year to reflect this market size normalization, via the formula $\tilde{q}_{t}^{i}=72.96 * s_{t}^{i}$, where $\tilde{q}_{t}^{i}$ denotes the adjusted quantity, and $s_{t}^{i}$ the observed market share, for a model $i$ car in year $t$.

Prices were deflated using a 1983 dollar as the base. The prices for each of the ten composite goods were computed as quantity-weighted indices of the prices of several representative car models in each composite (size classifications of the included car models were taken from Ward's Automotive Yearbook). For each firm and size segment, we chose the representative car models by, first, including the top-selling car in each sample year for this firm and segment. Second, we included additional car models which were among the top ten selling car models during any sample year. Finally, for each car model included by the first two criteria, we also included any car models which were stylistic antecedents or successors to this model (for example, the Ford Taurus was a top seller 
in the latter 1980s; thus we included not only the Ford Taurus, but also the Ford LTD, which it replaced). In using these criteria, our aim was not only to have at least one representative car model for each firm and segment during each sample year, but also to include top sellers for each year. Finally, by the third criterion we tried to ensure uniformity in cars over time, so that we would not be comparing the prices of very different cars across years.

Following these criteria, the representative car models included in each composite (and the model years for which we had data) are given here:

Chrysler Subcompact: Colt (71-90).

Chrysler Compact: Dart (64-76), Volare (76-80), Aries (81-89), Reliant (81-89).

Chrysler Mid/Full-size: New Yorker (71-73, 78-79, 81-90).

Ford Subcompact: Pinto (71-80), Escort (81-90).

Ford Compact: Maverick (70-77), Fairmont (78-83), Tempo (84-90).

Ford Mid/Full-size: Fairlane (64-70), LTD (69-86), Torino (70-76), Granada (75-80, 82), Taurus (86-90).

GM Subcompact: Vega (71-77), Chevette (76-87), Cavalier (82-90).

GM Compact: Skylark (64-90), Malibu (77-83), Citation (80-85), Corsica (87-90), Nova (64-79, 85-88).

GM Mid/Full-size: Cutlass (65-90), Delta (69-88), Grand Prix (69-90), Monte Carlo (70-88), Century (73-90), Impala (75-85), Regal (79-90), Celebrity (82-90).

Imports: Honda Accord (76-90), Datsun 210 (77-79, 81-82), Nissan Sentra (84-90), Hyundai Excel (86-90), Honda Civic (74-90), Camry (83-90). 


\section{References}

ADDA, J., AND R. COOPER. "Balladurette and Jupette: A Discrete Analysis of Scrapping Subsidies," Journal of Political Economy, Vol. 108 (2000), 778-806.

AKerlof, G. "The Market for "Lemons": Quality Uncertainty and the Market Mechanism," Quarterly Journal of Economics, Vol. 84 (1970), 488-500.

Anderson, S., And V. Ginsburgh. "Price Discrimination via Second-hand Markets," European Economic Review, Vol. 38 (1994), 23-44.

Attanasio, O. "Consumer Durables and Inertial Behavior: Estimation and Aggregation of (s,S) Rules," Review of Economic Studies, Vol. 67 (2000), 667-696.

Ausubel, L., And R. Deneckere. "Reputation in Bargaining and Durable Goods Monopoly," Econometrica, Vol. 58 (1989), 511-531.

BAşAR, T., AND G. Olsder. Dynamic Noncooperative Game Theory. SIAM Classics in Applied Mathematics, 1982.

Berkovec, J. "New Car Sales and Used Car Stocks: A Model of the Automobile Market," RAND Journal of Economics, Vol. 16 (1985), 195-214.

BERRY, S. "Estimating Discrete Choice Models of Product Differentiation," RAND Journal of Economics, $25,242-262$.

Berry, S., J. Levinsohn, And A. PaKes. "Automobile Prices in Market Equilibrium," Econometrica, Vol. 63 (1995), 841-890.

— . "Voluntary Export Restraints on Automobiles: Evaluating a Strategic Trade Policy," American Economic Review, Vol. 89 (1999), 400-430.

Berry, S., And A. PaKes. "Estimating the Pure Hedonic Discrete Choice Model," Manuscript, Yale University, 1999.

Bond, E. “A Direct Test of the "Lemons" Model: The Market for Used Pickup Trucks," American Economic Review, Vol. 72 (1982), 836-840.

Bresnahan, T. "Departures from Marginal Cost Pricing in the American Automobile Industry," Journal of Econometrics, Vol. 17 (1982), 201-227.

Bresnahan, T., And V. Ramey. "Output Fluctuations at the Plant Level," Quarterly Journal of Economics, Vol. 108 (1994), 593-624.

BulOw, J. “Durable-Goods Monopolists," Journal of Political Economy, Vol. 90 (1982), 314-332.

729-749.

Carlton, D., And R. Gertner. "Market Power and Mergers in Durable-Good Industries," Journal of Law and Economics, Vol. 32 (1989), S203-S231.

Chevalier, J., And A. Goolsbee. “Are Durable Goods Consumers Forward Looking?, NBER working paper 11421, 2005.

COASE, R. “Durability and Monopoly,” Journal of Law and Economics, Vol. 15 (1972), 143-149. 
Cohen, D., And A. Greenspan. "Motor Vehicle Stocks, Scrappage, and Sales," Manuscript, Federal Reserve Board, 1996.

EBERLY, J. “Adjustment of Consumers' Durables Stocks: Evidence from Automobile Purchases,” Journal of Political Economy, Vol. 102 (1994), 403-436.

Esteban, S. "Semi-Durable Goods and Imperfect Competition," Ph.D. thesis, University of Rochester, 1999.

— . "Equilibrium Dynamics in Semi-Durable Goods Markets," Manuscript, Universidad Carlos III, 2006.

Fudenberg, D., And J. Tirole. Game Theory. MiT Press, 1991.

GoldberG, P. "Product Differentiation and Oligopoly in International Markets: The Case of the US Automobile Industry," Econometrica, Vol. 63 (1995), 891-951.

Gul, F., H. Sonnenschein, And R. Wilson. "Foundations of Dynamic Monopoly and the Coase Conjecture,” Journal of Economic Theory, Vol. 39 (1986), 155-190.

Hendel, I., AND A. Lizzeri. “Adverse Selection in Durable Goods Markets,” American Economic Review, Vol. 89 (1999), 1097-1115.

House, C., And J. Leahy. “An (s,S) Model with Adverse Selection,” Journal of Political Economy, Vol. 112 (2004), 581-614..

IIZUKA, T. “An Empirical Analysis of Planned Obsolescence,” Journal of Economics and Management Strategy, Vol. 17 (2007), 191-226.

JuDD, K. "Cournot vs. Bertrand: a Dynamic Resolution,” Manuscript, Hoover Institution, Stanford University, 1996.

KaHn, C. "The Durable Goods Monopolist and Consistency with Increasing Returns," Econometrica, Vol. 54 (1986), 275-294.

KyDland, F. "Noncooperative and Dominant Player Solutions in Discrete Dynamic Games," International Economic Review, Vol. 16 (1975), 321-335.

LiAnG, M. "Does a Second-Hand Market Limit a Durable Goods Monopolist's Market Power?," Manuscript, Academia Sinica, 1999.

Petrin, A. "Quantifying the Benefits of New Products: the Case of the Minivan," Journal of Political Economy, Vol. 110 (2002), 705-729.

Porter, R., And P. SATTLER. "Patterns of Trade in the Market for Used Durables: Theory and Evidence," NBER working paper, \#7149, 1999.

Prescott, E., AND M. Visscher. "Sequential Location among Firms with Foresight," Bell Journal of Economics, Vol. 8 (1977), 378-393.

RAMEY, V. (1989): “Durable Goods Monopoly Behavior in the Automobile Industry," Manuscript, UC-San Diego.

RUST, J. “Stationary Equilibrium in a Market for Durable Assets,” Econometrica, Vol. 53 (1985a), $783-805$.

. "When is it Optimal to Kill off the Market for Used Durable Goods?," Econometrica, Vol. 54 (1985b), 65-86. 
SARgent, T. Dynamic Macroeconomic Theory. Harvard University Press, 1987.

Stokey, N. "Rational Expectations and Durable Goods Pricing," Bell Journal of Economics, Vol. 12 (1981), $112-128$.

Stolyarov, D. "Turnover of Used Durables in a Stationary Equilibrium: are Older Goods traded More?," Journal of Political Economy, Vol. 110 (2002), 1390-1413.

SusLOw, V. "Short-Run Supply with Capacity Constraints," RAND Journal of Economics, Vol. 17 (1986), 389-403.

Swan, P. "Optimal Durability, Second-Hand Markets, and Planned Obsolescence," Journal of Political Economy, Vol. 53 (1985), 575-585.

Waldman, M. "Durable Goods Theory for Real World Markets," Journal of Economic Perspectives, Vol. 17 (2003), 131-154. 
Table 1: Estimation results: Non- quality ladder parameters Marginal Costs (\$'000): specification is $M C(x)=\beta_{0}+2 \beta_{1} x$

$\begin{array}{lccrr}\text { Manufacturer } & \text { Segment } & \text { Parameter } & \text { Estimate } & \text { Std. Error } \\ \text { Chrysler } & \mathrm{SC} & \beta_{1} & 1.956 & 16.198 \\ \text { Chrysler } & \mathrm{SC} & \beta_{2} & 13.206 & 56.502 \\ \text { Chrysler } & \mathrm{C} & \beta_{1} & 3.315 & 8.359 \\ \text { Chrysler } & \mathrm{C} & \beta_{2} & 4.192 & 11.234 \\ \text { Chrysler } & \mathrm{MF} & \beta_{1} & 4.522 & 13.948 \\ \text { Chrysler } & \mathrm{MF} & \beta_{2} & 12.286 & 44.353 \\ \text { Ford } & \mathrm{SC} & \beta_{1} & 2.780 & 14.028 \\ \text { Ford } & \mathrm{SC} & \beta_{2} & 9.468 & 21.007 \\ \text { Ford } & \mathrm{C} & \beta_{1} & 3.293 & 22.293 \\ \text { Ford } & \mathrm{C} & \beta_{2} & 11.588 & 32.309 \\ \text { Ford } & \mathrm{MF} & \beta_{1} & 5.849 & 37.141 \\ \text { Ford } & \mathrm{MF} & \beta_{2} & 6.470 & 30.667 \\ \text { GM } & \mathrm{SC} & \beta_{1} & .924 & 7.990 \\ \text { GM } & \mathrm{SC} & \beta_{2} & 8.799 & 14.891 \\ \text { GM } & \mathrm{C} & \beta_{1} & 1.505 & 12.695 \\ \text { GM } & \mathrm{C} & \beta_{2} & 7.440 & 13.240 \\ \text { GM } & \mathrm{MF} & \beta_{1} & 4.444 & 18.312 \\ \text { GM } & \mathrm{MF} & \beta_{2} & 2.760 & 7.785 \\ & & & & \\ \text { \# moment restrictions } & 395^{a} & & & \end{array}$

\footnotetext{
${ }^{a}$ We used 5 demand instruments for each of the demand residuals corresponding to 70 model-years, and 5 supply instruments for each of the supply function residuals corresponding to the 9 composite new car models.
} 
Table 2: Simulated steady-state in the dynamic model

\begin{tabular}{|c|c|c|c|c|c|c|}
\hline \multirow[b]{2}{*}{ Manufacturer } & \multirow[b]{2}{*}{ Segment } & \multicolumn{2}{|c|}{ Actual values } & \multicolumn{3}{|c|}{ Simulated values } \\
\hline & & $\begin{array}{l}\text { Quantity }^{a} \\
\text { (millions) }\end{array}$ & $\begin{array}{r}\text { Price } \\
(' 000 s)\end{array}$ & $\begin{array}{r}\text { Quantity } \\
\text { ('000s) }\end{array}$ & $\begin{array}{r}\text { Price } \\
(' 000 s)\end{array}$ & $\begin{array}{r}\text { Marginal Cost } \\
\text { ('000s) }\end{array}$ \\
\hline Chrysler & $\mathrm{SC}$ & .176 & 5.344 & .158 & 6.254 & 6.137 \\
\hline Chrysler & $\mathrm{C}$ & .379 & 7.923 & .400 & 6.798 & 6.667 \\
\hline Chrysler & $\mathrm{MF}$ & .170 & 11.822 & .170 & 8.837 & 8.692 \\
\hline Ford & $\mathrm{SC}$ & .322 & 6.098 & .326 & 9.258 & 8.956 \\
\hline Ford & $\mathrm{C}$ & .267 & 7.457 & .298 & 10.547 & 10.197 \\
\hline Ford & MF & .628 & 9.958 & 637 & 14.609 & 14.093 \\
\hline GM & $\mathrm{SC}$ & .427 & 6.725 & .376 & 7.956 & 7.535 \\
\hline GM & $\mathrm{C}$ & .526 & 8.530 & .475 & 9.051 & 8.572 \\
\hline GM & MF & 1.430 & 10.253 & 1.263 & 12.054 & 11.416 \\
\hline
\end{tabular}

\footnotetext{
${ }^{a}$ Equilibrium values of endogenous variables evaluated at the steady-state of the dynamic model, using the parameter values illustrated in Figure 3. In the calculations, we used the $\alpha$ 's for the import cars set at their 1987-1990 values. Market shares are computed for the primary market and exclude imports, which are exogenous. We fixed the production of imports at 1.10 million cars, reflecting the average import volume during the sample period.
} 
Table 3: Simulated markups when consumer population size is reduced

$\begin{array}{lcrrrr}\text { Manufacturer } & \text { Segment } & \text { Baseline }^{a} & \text { 75\% pop'n } & \text { 50\% pop'n } & \text { 25\% pop'n } \\ \text { Chrysler } & \text { SC } & 1.860 & 2.270 & 2.952 & 4.2634 \\ \text { Chrysler } & \text { C } & 1.926 & 2.312 & 2.931 & 3.9894 \\ \text { Chrysler } & \text { MF } & 1.641 & 1.830 & 2.020 & 1.6065 \\ \text { Ford } & \text { SC } & 3.263 & 3.935 & 5.032 & 7.1601 \\ \text { Ford } & \text { C } & 3.314 & 3.905 & 4.801 & 6.1524 \\ \text { Ford } & \text { MF } & 3.533 & 4.029 & 4.697 & 5.2537 \\ \text { GM } & \text { SC } & 5.301 & 6.639 & 8.977 & 14.291 \\ \text { GM } & \text { C } & 5.294 & 6.558 & 8.709 & 13.281 \\ \text { GM } & \text { MF } & 5.296 & 6.410 & 8.188 & 11.313\end{array}$

\footnotetext{
${ }^{a}$ Computed using the marginal costs reported in Table 2. Baseline population value is 72.95 million households. We fixed the production of imports at 1.10 million cars, reflecting the average import volume during the sample period.
} 
Table 4: Changes in output with the temporary elimination of the secondary market

\begin{tabular}{|c|c|c|c|c|c|c|}
\hline Manufacturer & Segment & $\begin{array}{c}\text { Output, } \\
\text { baseline } \\
\text { (millions) }\end{array}$ & $\begin{array}{r}\text { Big } 3 \text { mkt share, } \\
\text { baseline } \\
(\%)\end{array}$ & $\begin{array}{r}\text { Output, with } \\
\text { zero used stock } \\
\text { (millions) }\end{array}$ & $\begin{array}{r}\text { Big } 3 \text { mkt share, with } \\
\text { zero used stock }\end{array}$ & $\% \Delta$ output $^{a}$ \\
\hline Chrysler & $\mathrm{SC}$ & .158 & 3.86 & .186 & 4.04 & 17.3 \\
\hline Chrysler & $\mathrm{C}$ & .400 & 9.74 & .488 & 10.62 & 22.10 \\
\hline Chrysler & MF & .170 & 4.14 & .200 & 4.36 & 18.05 \\
\hline Ford & $\mathrm{SC}$ & .326 & 7.95 & .366 & 7.95 & 12.13 \\
\hline Ford & $\mathrm{C}$ & .298 & 7.26 & .330 & 7.18 & 10.80 \\
\hline Ford & MF & .637 & 15.53 & .693 & 15.08 & 8.80 \\
\hline GM & $\mathrm{SC}$ & .376 & 9.16 & .417 & 9.07 & 10.98 \\
\hline GM & $\mathrm{C}$ & .475 & 11.58 & .524 & 11.40 & 10.37 \\
\hline GM & MF & 1.263 & 30.79 & 1.394 & 30.31 & 10.35 \\
\hline \multicolumn{7}{|c|}{ Total by manufacturer } \\
\hline Chrysler & & .728 & 17.74 & .874 & 19.01 & 20.11 \\
\hline Ford & & 1.261 & 30.74 & 1.389 & 30.21 & 10.13 \\
\hline GM & & 2.113 & 51.52 & 2.335 & 50.78 & 10.47 \\
\hline \multicolumn{7}{|c|}{ Total by segment } \\
\hline & $\mathrm{SC}$ & .860 & 20.97 & .968 & 21.06 & 12.58 \\
\hline & $\mathrm{C}$ & 1.173 & 28.58 & 1.342 & 29.20 & 14.48 \\
\hline & MF & 2.070 & 50.45 & 2.287 & 49.74 & 10.51 \\
\hline \multirow{2}{*}{\multicolumn{7}{|c|}{ Total primary market }} \\
\hline & & 4.102 & & 4.598 & & 12.08 \\
\hline
\end{tabular}

${ }^{a}$ Changes in output are computed for the period when the stock of used cars in the entire secondary market is eliminated relative to the baseline steady state
output (as reported in column 3) and using the $\alpha$ for the import cars set at its 1987-1990 level. Baseline population value is 72.95 million households. We fixed
the production of imports at 1.10 million cars, reflecting the average import volume during the sample period. The market share is computed within the Big 3,
which excludes imports. Output when the stock of used cars equals zero is equal to the constant coefficient in the equilibrium decision rule in Eq. (A2).


Esteban and Shum

Figure 1 of 3

Figure 1: Simulations of durable goods monopoly model: changes in $\alpha$
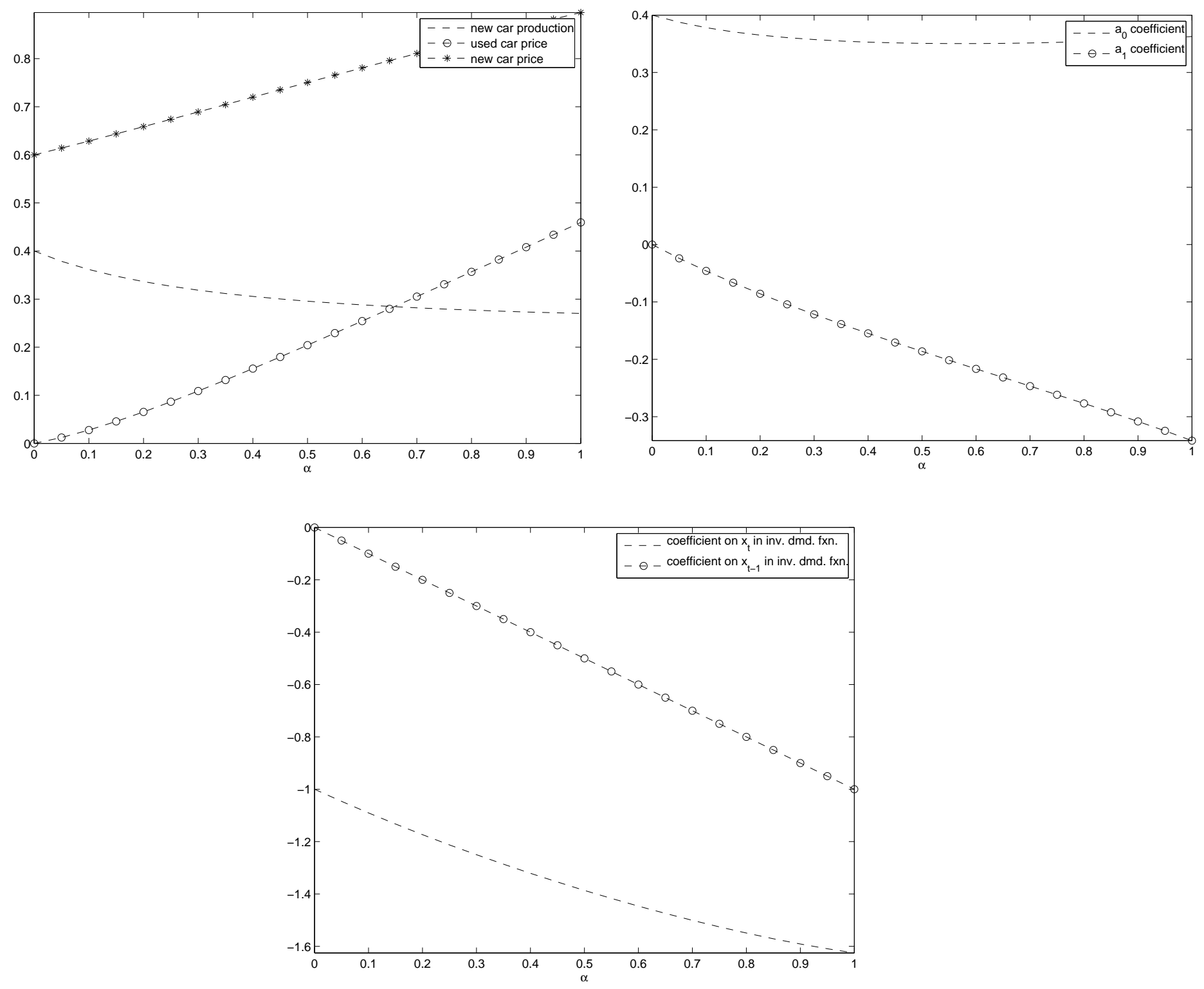
Esteban and Shum

Figure 2 of 3

Figure 2: Simulations of durable goods monopoly model: changes in marginal cost

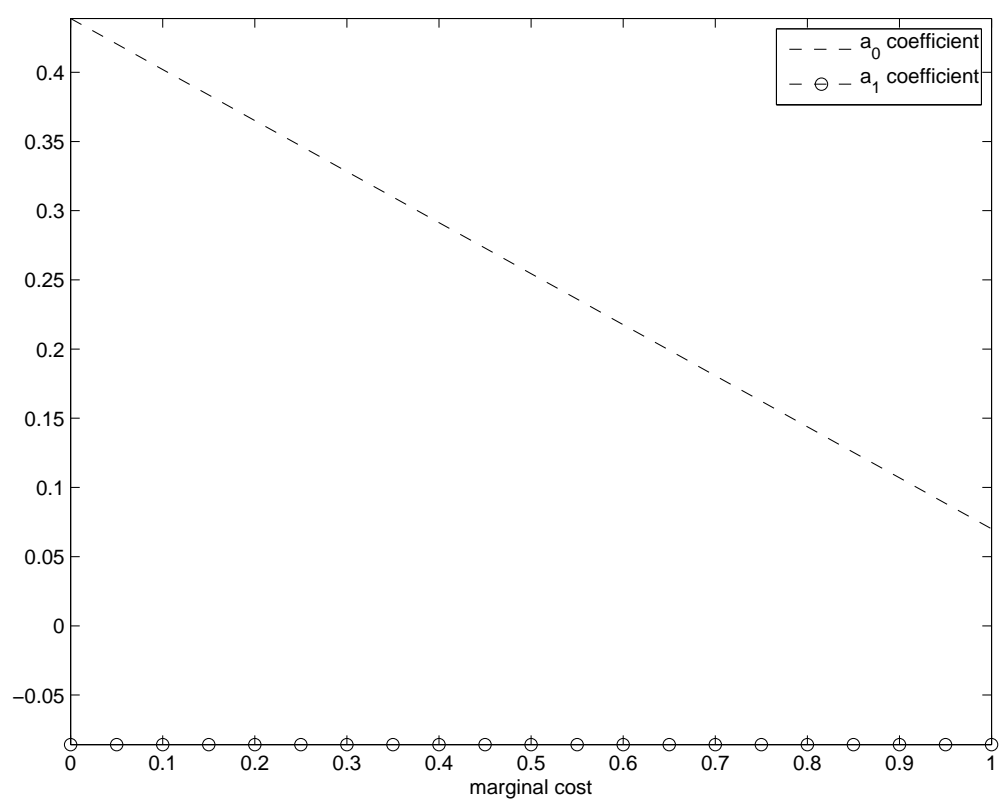


Figure 3: Graphs of the estimated car quality $\alpha$ parameters

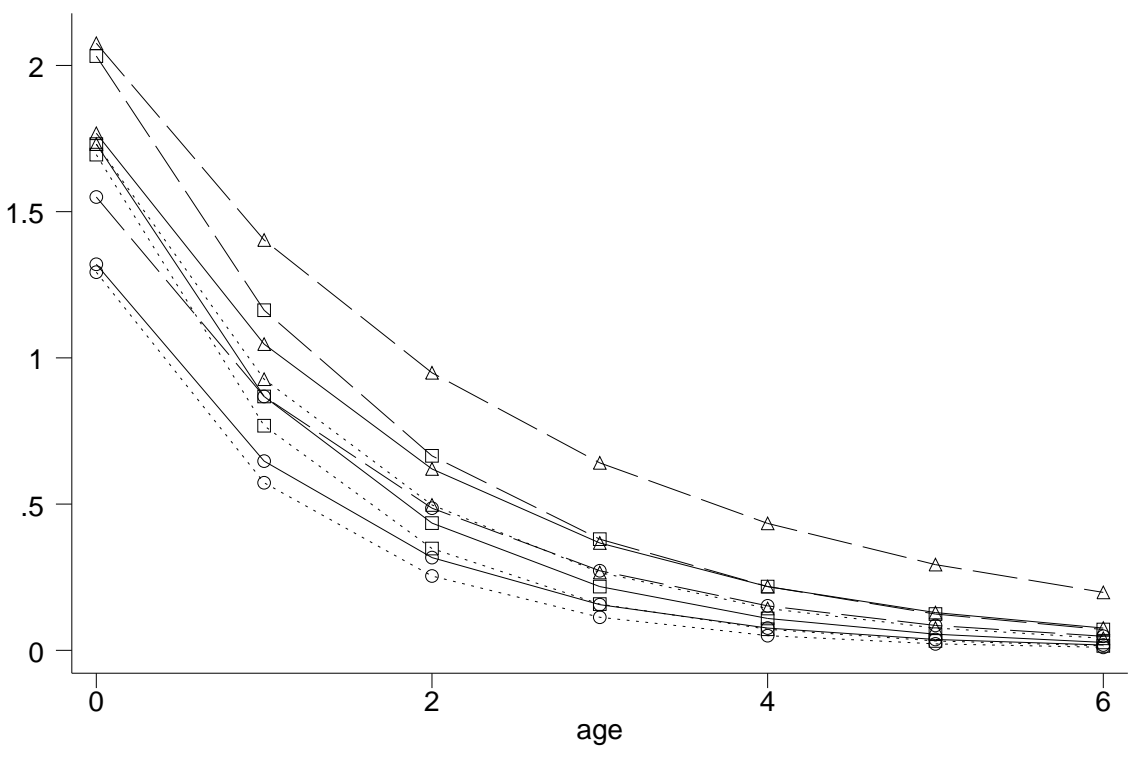

Estimated $\alpha$ 's for domestic car models:

Circle for Chrysler models, Triangle for Ford models, Square for GM models Solid line for subcompacts, dotted line for compacts and dashed line for midsize

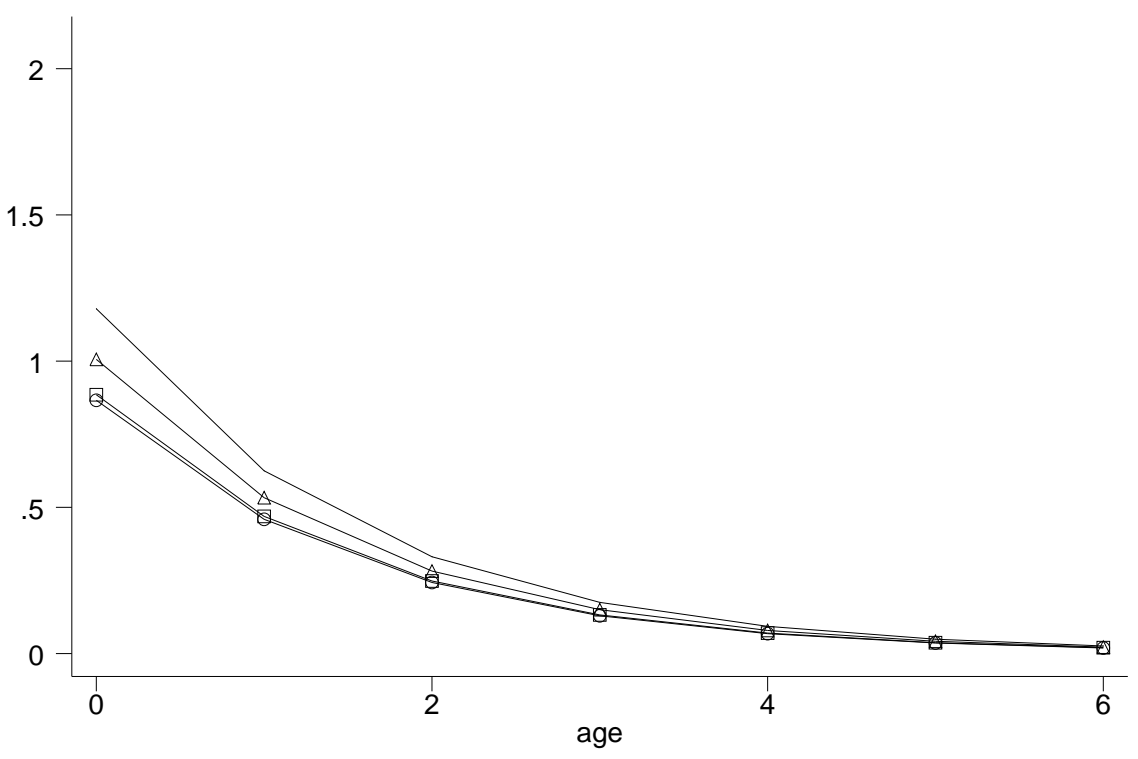

Estimated $\alpha$ 's for imports:

Circle for 1971-78, Triangle for 1979-82, Square for 1983-86, Solid line for 1987-90

Note: age "0" denotes new car 